\title{
Modulation of Transient receptor potential melastatin 3 by protons through its intracellular binding sites
}

Md Zubayer Hossain Saad ${ }^{1,2, \# \text {, Liuruimin Xiang }}{ }^{1,2, \#, \text { Yan-Shin Liao }}{ }^{3}$, Leah R. Reznikov ${ }^{3}$, Jianyang $\mathrm{Du}^{1,2,4, *}$

${ }^{1}$ Department of Anatomy and Neurobiology, University of Tennessee Health Science Center, Memphis, TN 38163, USA.

${ }^{2}$ Department of Biological Sciences, University of Toledo, Toledo, OH 43606, USA.

${ }^{3}$ Department of Physiological Sciences, University of Florida, Gainesville, FL 32610, USA.

${ }^{4}$ Neuroscience Institute, University of Tennessee Health Science Center, Memphis, TN 38163, USA.

\# These authors contributed equally to this work

\section{Correspondence}

Jianyang Du, Tel: 901-448-3463, Email: jdu15@uthsc.edu

Running Title: Intracellular acidic pH inhibits TRPM3. 


\section{Abstract}

2 Transient receptor potential melastatin 3 channel (TRPM3) is a calcium-permeable

3 nonselective cation channel that plays an important role in modulating glucose homeostasis

4 in the pancreatic beta cells. However, how TRPM3 is regulated under physiological and

5 pathological conditions is poorly understood. In this study, we found that both intracellular

6 and extracellular protons block TRPM3 through its intracellular binding sites. We

7 demonstrated that external protons indirectly block TRPM3, whereas internal protons

8 inhibit TRPM3 directly with an inhibitory $\mathrm{pH}_{50}$ of $6.9 \pm 0.11$. We identified three titratable

9 residues, D1059, D1062, and D1073, at the inner vestibule of the channel pore that

10 contribute to $\mathrm{pH}$ sensitivity. The mutation of D1073Q reduces TRPM3 current intensity

11 and $\mathrm{pH}$ sensitivity; Replacement of Asp 1073 by Gln 1073 changes the reduction of

12 TRPM3 outward current by low external $\mathrm{pH} 5.5$, from $62 \pm 3 \%$ in WT to $25 \pm 6.0 \%$ in

13 D1073Q. These results indicate that D1073 is not only essential for intracellular $\mathrm{pH}$

14 sensitivity, but it is also crucial for TRPM3 channel gating. In addition, a single mutation

15 of D1059 or D1062 enhances pH sensitivity. In summary, our findings provide a novel

16 molecular determinant for $\mathrm{pH}$ regulation of TRPM3. The inhibition of TRPM3 by protons

17 may indicate an endogenous mechanism governing TRPM3 gating and its physiological/

18 pathological functions.

19

20 Keywords: TRP channels, TRPM3, protons, Pregnenolone Sulfate, Site-directed

21 Mutagenesis, extracellular low $\mathrm{pH}$, intracellular low $\mathrm{pH}, \mathrm{pH}$ sensitivity. 


\section{Introduction}

25 Transient receptor potential channels (TRP channels) are membrane proteins that facilitate

26 the interpretation of external stimuli, and allow organisms to readily sense the environment

27 (Clapham 2003). These stimuli include temperature (Vandewauw et al. 2018; Brauchi and

28 Orio 2011), voltage (Clapham 2003; Brauchi and Orio 2011; Montell et al. 1985),

29 mechanical force (osmolarity (Strotmann et al. 2000; Liedtke and Friedman 2003; Quallo

30 et al. 2015), pressure (Suzuki et al. 2003), stretch (Strotmann et al. 2000; Hardie and Franze

31 2012; Maroto et al. 2005), gravity (Sun et al. 2009)), light (Montell et al. 1985; Minke

32 1977; Hardie 2014), proton concentration (Gerdes et al. 2007; Chandrashekar et al. 2006;

33 Semtner et al. 2007), and various chemical signals (Caterina et al. 1997; McKemy,

34 Neuhausser, and Julius 2002; Everaerts et al. 2011). TRP channels form homomeric or

35 heteromeric cation channels that can be selective or non-selective to cations; and most of

36 the TRP members are permeable to $\mathrm{Ca}^{2+}$ (Pan, Yang, and Reinach 2011). Upon activation,

37 TRP channels change membrane potential or intracellular calcium concentration $\left(\left[\mathrm{Ca}^{2+}\right] \mathrm{i}\right)$

38 to promote downstream signal transductions. Depending on sequence homology and

39 channel architecture, TRP channels are divided into seven subfamilies, namely, TRPA

40 (Ankyrin), TRPC (Canonical), TRPM (Melastatin), TRPML (Mucolipin), TRPP

41 (Polycystin), TRPV (Vanilloid), and TRPN (NompC, no vertebrate member). 27 vertebrate

42 members of these subfamilies are expressed in humans (Venkatachalam and Montell 2007;

43 Uchida et al. 2019).

44 TRPM3 belongs to the subfamily of TRPM (Melastatin). TRPM3 is a non-selective 45 cation channel that is permeable to $\mathrm{Ca}^{2+}, \mathrm{Na}^{+}, \mathrm{Mn}^{2+}$ and $\mathrm{Mg}^{2+}$ ions with a permeability ratio 46 of $\mathrm{P}_{\mathrm{Ca}} / \mathrm{P}_{\mathrm{Na}}$ of $1.57 \pm 0.31$ (Grimm et al. 2003). RT-qPCR analyses have shown expression 
47 of human (hTRPM3), mouse (mTRPM3) and rat (rTRPM3) TRPM3 in a variety of tissues,

48 with the most abundant expression in the brain, kidney, pituitary gland and adipose tissues

49 (Oberwinkler and Philipp 2014; Zamudio-Bulcock et al. 2011). In sensory neurons,

50 TRPM3 functions as a noxious heat sensor; TRPM3 deficient mice lack the normal

51 response to noxious heat and do not develop inflammatory heat hyperalgesia (Vandewauw

52 et al. 2018; Vriens et al. 2011). Vangeel et al. recently demonstrated functional expression

53 of TRPM3 in human sensory neurons; where a large subset of nociceptor neurons express

54 TRPM3, and TRPM3 has been suggested to be a potential drug target for novel analgesics

55 (Vangeel et al. 2020; Moran and Szallasi 2018). Although, role of TRPM3 in central

56 nervous system has not been explored in detail yet, a recent study has shown high-level

57 expression of TRPM3 in mouse CA2 and CA3 hippocampal neurons and in the dentate

58 gyrus. Field potential recordings also showed that TRPM3 agonists inhibit synaptic

59 transmission and plasticity, and reduce long-term potentiation (LTP) in mouse

60 hippocampus (Held et al. 2020). Moreover, human genetic analyses have linked TRPM3

61 mutations with intellectual disability, epilepsy, inherited cataract and glaucoma (Dyment

62 et al. 2019; Bennett et al. 2014). In cardiovascular system, TRPM3 localizes in the

63 perivascular nerves of mouse mesenteric arteries, and induces vasodilation by stimulating

64 CGRP (calcitonin gene-related peptide) receptors (Alonso-Carbajo et al. 2019). TRPM3

65 forms homomultimeric channels, which are constitutively active (Grimm et al. 2003). In

66 addition, TRPM3 channel can also be activated by endogenous neurosteroid pregnenolone

67 sulfate (PS), nifedipine, and clotrimazole. Mefenamic acid, diclofenac, progesterone and

68 favanones have been reported to inhibit TRPM3 (Wagner et al. 2008; Uchida et al. 2019).

69 PS has been shown to increase neurotransmitter release, strengthen synaptic transmission 
70 and modulate synaptic plasticity (Smith, Gibbs, and Farb 2014). However, whether

71 TRPM3 contribute to any of these neuronal functions of PS or not, is not clear (Zamudio-

72 Bulcock et al. 2011). One study has shown that PS-induced potentiation of spontaneous

73 glutamate release in Purkinje neurons of developing rats is mediated by TRPM3 (Zamudio-

74 Bulcock et al. 2011). In non-neuronal cells, PS upregulates activator protein 1 (AP-1) and

75 early growth response protein 1 (Egr-1) transcriptional activity, which can be blocked by

76 TRPM3 antagonists (Lesch, Rubil, and Thiel 2014). TRPM3 also upregulates c-Jun and c-

77 Fos promoter activity and stimulates CRE-controlled reporter gene transcription in

78 insulinoma and pancreatic $\beta$-cells, in a TRPM3-dependent manner (Muller, Rossler, and

79 Thiel 2011). In vascular smooth muscle cells, PS increases $\left[\mathrm{Ca}^{2+}\right]_{i}$ and modulates

80 contractile responses, which can be inhibited by TRPM3 inhibitors (Naylor et al. 2010).

81 PS also increases $\left[\mathrm{Ca}^{2+}\right]_{\mathrm{i}}$ in fibroblast-like synoviocytes and suppresses the secretion of

82 hyaluronan via TRPM3 (Ciurtin et al. 2010).

83 Extracellular and intracellular protons modulate ion channel activity. For example,

84 extracellular acidification activates acid-sensing ion channels (ASICs), G-protein coupled

85 inward rectifier $\mathrm{K}^{+}$channels, nifedipine sensitive L-type $\mathrm{Ca}^{2+}$ channels, and acid-sensitive

$86 \mathrm{Cl}^{-}$channels; while inhibiting two-pore domain $\mathrm{K}^{+}$channels (TASK-1, TASK-2, TASK-3,

87 TALK-1, and TALK-2), and reducing potency of ionotropic purinoceptors - P2X1, P2X3,

$88 \mathrm{P} 2 \mathrm{X} 4$ and $\mathrm{P} 2 \mathrm{X} 7$. Intracellular acidosis activates inward rectifier $\mathrm{K}^{+}$channel family protein

89 Kir6.1, K2p channel TREK-1 and TREK-2; however, Kir1.1, Kir4.1, and Kir5.1 activity

90 is inhibited by both intracellular and extracellular decreases in $\mathrm{pH}$. Gap junction channels,

91 connexins, are also inhibited by intracellular acidosis. In addition, both intracellular and

92 extracellular acidification block the K2p channel TRESK, as well as depress or inhibit 
93 TWIK-1 and TWIK-2. Some of the ion channels, such as, TASK-2, TRESK, TALK-1, and

94 TALK-2, which are blocked at low $\mathrm{pH}$ can be activated or gated open by alkalization.

95 Protons cannot activate or inhibit P2X2 and P2X5 homomultimers but decreases potency

96 and efficacy of ATP gating of P2X5, and sensitizes P2X2 receptors to ATP. To make things

97 even complex, protons can have a variable effect depending on the subunit composition of

98 heteromeric ion channels (Holzer 2009). TRP channels are no exception regarding variable

99 activity in response to $\mathrm{pH}$. Specifically, TRPV1, TRPV4, and TRPC4 are activated by a

100 reduction of $\mathrm{pH}$. In contrast, TRPC5 currents are increased by an acidic $\mathrm{pH}$ until 6.0 is

101 reached, at which point further decreases in $\mathrm{pH}$ reduce current (Holzer 2009). PKD2L1

102 (TRPP2) expressing neurons show action potentials in response to citric acid (Huang et al.

103 2006), whereas intracellular and extracellular $\mathrm{pH}$ inhibits TRPM2 (Du, Xie, and Yue

104 2009). Yet very little is known about how $\mathrm{pH}$ regulates TRPM3. Thus, to understand the

105 role of $\mathrm{pH}$ on TRPM3 activity, we studied how TRPM3 activation by PS responds to

106 different extracellular and intracellular $\mathrm{pH}$ conditions. In all experiments, we activated

107 TRPM3 by external application of PS, and all subsequent mentions of TRPM3 activity in

108 this manuscript must be considered as TRPM3 activity in response to PS, and not TRPM3

109 constitutive activity. As PS induced TRPM3 currents are almost two orders of magnitude

110 higher than TRPM3 constitutive currents (Wagner et al. 2008; Grimm et al. 2003; Lee et

111 al. 2003), we concluded that for our experiments, it is reasonable to exclude the effects of

112 constitutive TRPM3 activity. 


\section{Materials \& Methods}

\section{Plasmid and molecular biology}

118 The cDNA of human TRPM3 channel (accession number AJ505026) with C-terminal GFP 119 tag was provided by C. Harteneck (University of Tübingen, Tübingen, Germany) (Grimm 120 et al. 2003). Alternative splicing patterns of TRPM3 is highly conserved across human and 121 rodents (Oberwinkler et al. 2005). To date, 25 isoforms of mTRPM3 protein have been 122 identified, including a recently discovered variant - TRPM3 $\gamma 3$. Splicing events affect exons $1238,13,15,17,20,24$ and 28 of TRPM3. $\alpha$ variants lack exon $2, \beta$ variants lack exon 1 , and

$124 \gamma$ variants lack a large part of exon 28 (Uchida et al. 2019; Oberwinkler and Philipp 2014).

125 Our hTRPM3 cDNA contains all 30 exons, where 389 amino acids in exon 28 has been 126 replaced with alternative carboxy terminus of 7 residues; this truncation does not affect any 127 functional activity of the ion channel (Oberwinkler and Philipp 2014; Grimm et al. 2003). 128 Mutations of hTRPM3-GFP were generated by site-directed mutagenesis (performed by 129 GENEWIZ Inc). The predicted mutations were verified by sequencing analysis.

Cell culture and overexpression of hTRPM3-GFP and the mutants in HEK-293 cells.

132 Human embryonic kidney (HEK) 293 cells were used to transiently overexpress wild-type 133 hTRPM3-GFP and its mutants. The cells were grown in DMEM/F12 medium (Fisher 134 Scientific, catalog no. MT10090CV) supplemented with 10\% bovine growth serum 135 (HyClone, catalog no. SH30541.03), $100 \mathrm{U} / \mathrm{ml}$ penicillin / $100 \mathrm{mg} / \mathrm{ml}$ streptomycin (Fisher 136 Scientific, catalog no. SV30010) at $37^{\circ} \mathrm{C}$ in a $5 \% \mathrm{CO}_{2}$ - controlled, humidity-controlled 137 incubator. Lipofectamine 2000 (Thermo Fisher Scientific, catalog no. 18324012) was used 138 for the transfection of TRPM3 into the cells in a 35-mm culture dish according to the 
139

140

141

142

\section{Electrophysiology}

144 All patch-clamp experiments were performed at room temperature $\left(20-22^{\circ} \mathrm{C}\right)$. TRPM3

145 whole-cell currents were recorded using an Axopatch 200B amplifier. Data were digitized 146 at $10 \mathrm{kHz}$ and digitally filtered offline at $5 \mathrm{kHz}$. Patch electrodes were pulled by Sutter P-

14797 micropipette puller and fire-polished to resistance of 3-5 $\mathrm{M} \Omega$ when filled with internal

148 solutions. Series resistance (Rs) was compensated up to $90 \%$ to reduce series resistance

149 errors to $<5 \mathrm{mV}$. Cells in which Rs was $>8 \mathrm{M} \Omega$ were discarded (Du, Xie, and Yue 2009).

150 For whole-cell current recording, ramp voltage stimuli (250 ms duration) were delivered 151 at 1 -second intervals and the ranging from -100 to $+100 \mathrm{mV}$. The internal pipette solution

152 for whole-cell current recordings contained (in $\mathrm{mM}$ ): 115 Cs-methanesulfonate $153\left(\mathrm{CsSO}_{3} \mathrm{CH}_{3}\right), 8 \mathrm{NaCl}, 10 \mathrm{Cs}-\mathrm{EGTA}, 5 \mathrm{Na}_{2}$-ATP and 10 HEPES, with $\mathrm{pH}$ adjusted to 7.2 154 with $\mathrm{CsOH}$. In high intracellular $\mathrm{Ca}^{2+}$ experiments, $0.93 \mathrm{mM} \mathrm{CaCl} 2$ was added to the 155 above-mentioned intracellular solution and EGTA was reduced to $1 \mathrm{mM}$, resulting in $1 \mu \mathrm{M}$ 156 free intracellular $\mathrm{Ca}^{2+}$. MaxChelator (https://somapp.ucdmc.ucdavis.edu/ pharmacology/ 157 bers/maxchelator/downloads.htm) software from the University of California, Davis was 158 used to calculate free $\left[\mathrm{Ca}^{2+}\right]_{\mathrm{i}}$.

159 To avoid proton activated chloride currents conducted by endogenous anion channels of 160 HEK-293 cells (Lambert and Oberwinkler 2005), $\mathrm{NaCl}$ in standard Tyrode solution was 161 replaced with Na-glutamate for all whole-cell current recordings. This external solution 
162 contained (in $\mathrm{mM}$ ): $145 \mathrm{Na}$-glutamate, $5 \mathrm{KCl}, 2 \mathrm{CaCl}_{2}, 1 \mathrm{MgCl}_{2}, 10 \mathrm{HEPES}$, and 10

163 glucose, with $\mathrm{pH}$ adjusted to 7.4 with glutamic acid. Internal and external acidic $\mathrm{pH}$

164 solutions were prepared as described previously with slight modifications (Du, Xie, and

165 Yue 2009). In brief, $10 \mathrm{mM}$ HEPES used in the solutions at $\mathrm{pH} 7.4$ and 7.0 was replaced

166 by $10 \mathrm{mM}$ MES for the solutions at $\mathrm{pH} \leq 6.0$. Bath solutions containing $1 \mathrm{mM}$ to $60 \mathrm{mM}$

$167 \mathrm{NH}_{4} \mathrm{Cl}$ were prepared by decreasing $\mathrm{Na}^{+}$concentrations to $85 \mathrm{mM}$ in the solution to keep

168 the osmolarity constant, and osmolarity was adjusted to $300 \pm 10 \mathrm{mOsm}$ with mannitol. In

169 experiments designed to test protons permeability of TRPM3, pipette solutions contained

170 (in mM): 120 NMDG, 108 glutamic acid, 10 HEPES, 10 EGTA, with pH adjusted to 7.2

171 with NMDG. External solutions for proton permeability test contained (in mM): 145

172 NMDG, 10 HEPES and 10 Glucose; and $\mathrm{pH}$ was adjusted with glutamic acid. To prepare

173 the $\mathrm{pH} 5.5$ external solution for proton permeability, $10 \mathrm{mM}$ HEPES was replaced with 10

$174 \mathrm{mM}$ MES. PS was dissolved in DMSO to prepare $100 \mathrm{mM}$ stock solution, and adequate

175 volume of stock PS solution was added to the external solution to achieve required

176 concentration. All the chemicals used in electrophysiological experiments were from

177 Sigma-Aldrich.

178

179 Data analysis

180 Statistical data were analyzed using GraphPad Prism 8. Pooled data are presented as mean $181 \pm$ SEM. Concentration-response curves were fitted by an equation of the form: $E=$ $182 E_{\max }\left\{1 /\left[1+\left(I C_{50} / C\right)^{n}\right]\right\}$ where $E$ is the effect at concentration $C, E_{\max }$ is the maximal effect, $183 \mathrm{IC}_{50}$ is the concentration for half-maximal effect, and $\mathrm{n}$ is the Hill coefficient (Du, Xie, and 184 Yue 2009). Concentration of proton required for half-maximal inhibition is denoted by $\mathrm{IC}_{50}$ 
185 (when $\mathrm{H}^{+}$concentration is expressed as molar concentration) and $\mathrm{pH}_{50}$ (when $\mathrm{H}^{+}$

186 concentration is expressed by $\mathrm{pH}$ value). Statistical comparison of two groups was

187 performed by unpaired Student's t-test, $\mathrm{p}<0.05$ was considered statistically significant.

188 Statistical comparison of three or more groups was performed by one-way ANOVA with

189 Tukey’s post hoc multiple comparison.

190

191 Results

192 Extracellular and intracellular acidic pH inhibit TRPM3

193 We studied the effects of low $\mathrm{pH}$ on TRPM3 by overexpressing hTRPM3-GFP in HEK-

194293 cells and recording whole-cell currents in response to PS. We found that low 195 extracellular $\mathrm{pH}$ inhibits TRPM3, in a reversible manner (Fig. 1, A - D). To avoid proton 196 activated endogenous anion channel conducted chloride currents, external $\mathrm{Cl}^{-}$was replaced 197 by glutamate (See Methods). Inhibitory effect of low extracellular $\mathrm{pH}\left(\mathrm{pH}_{\mathrm{o}}\right)$ was only 198 observed below $\mathrm{pH}$ 6.0. Specifically, at $\mathrm{pH}_{\mathrm{o}} 7.0$ and 6.0, recorded TRPM3 currents were 199 equivalent to $\mathrm{pH}_{\mathrm{o}} 7.4$ ( $\mathrm{p}>0.05$ in both groups). At a $\mathrm{pH}_{\mathrm{o}}$ below 6.0 , acidic conditions 200 exhibited significant inhibition of TRPM3 (Fig. 1). $\mathrm{pH}_{\mathrm{o}} 5.5$, caused $\sim 60 \%$ reduction in 201 TRPM3 whole-cell current induced by PS. Fitting these data in a non-linear regression 202 curve did not result in a well-fitted curve; we did not observe a concentration-dependent 203 effect of extracellular $\mathrm{pH}$ on TRPM3 activity. This might suggest an indirect inhibition of 204 TRPM3 by low $\mathrm{pH}_{\mathrm{o}}$. In addition, as shown in Fig. 1A, application of low extracellular $\mathrm{pH}$ $205(\mathrm{pH} \leq 5.5)$ with PS produced an initial activation of TRPM3 before blocking it. This 206 suggested that the onset of low $\mathrm{pH}_{\mathrm{o}}$ inhibition is slower than the PS activation, supporting 207 the hypothesis that the inhibition of TRPM3 by low $\mathrm{pH}_{\mathrm{o}}$ is indirect. We thus hypothesized 
213 value of $6.90 \pm 0.11$ (outward current at $+100 \mathrm{mV}$ ) (Fig. 2C) and $\mathrm{pH}_{50}$ value of $6.90 \pm 0.15$

214 (inward current at $-100 \mathrm{mV}$ ) (Fig. 2D). There was no significant difference in the steady-

215 state inhibition between inward and outward currents, concluding that there are no voltage-

216 dependent effects of acidic $\mathrm{pH}_{\mathrm{i}}$ on inward and outward TRPM3 currents (Fig. 2, C and D).

217 To investigate the extent of modulation of TRPM3 by protons, we also introduced higher

$218 \mathrm{pH}_{\mathrm{i}}$ than the physiological $\mathrm{pH}_{\mathrm{i}}$ of 7.2. Recorded TRPM3 current plateaued at about $\mathrm{pH}_{\mathrm{i}}$ 7.6.

219 Protons had similar inhibitory effects on both outward and inward TRPM3 currents (Fig.

220 2, $\mathrm{A}$ and $\mathrm{B}$ ). Combined, our findings that $\mathrm{pH}_{\mathrm{o}} 6.0$ did not affect TRPM3 current but low

$221 \mathrm{pH}_{\mathrm{i}}$ had an inhibitory $\mathrm{pH}_{50}$ value of 6.9, suggested a higher $\mathrm{pH}$ sensitivity of TRPM3 in the

222 cytoplasmic side.

\section{Effect of low $\mathbf{p H}_{\mathrm{i}}$ on concentration-dependence of TRPM3 activation by PS}

225 PS binds directly to the extracellular side of the TRPM3 channel to activate it. TRPM3

226 channel stays both functional and unaffected by the presence of intracellular PS (Wagner

227 et al. 2008). Previous studies have shown that PS activates TRPM3 in a concentration-

228 dependent manner with an $\mathrm{EC}_{50}$ value of $12 \mu \mathrm{M}$ and $23 \mu \mathrm{M}$ for outward and inward current

respectively (Wagner et al. 2008). To investigate the effect of protons on PS concentration-

230 dependence of TRPM3, we perfused the cells with a wide range of PS concentrations (1 
$231 \mu \mathrm{M}-500 \mu \mathrm{M}$ ), while keeping $\mathrm{pH}_{\mathrm{i}}$ constant at 7.2 or 6.0. TRPM3 whole-cell outward and

232 inward currents showed very similar PS concentration-dependence in both $\mathrm{pH}$ conditions

233 (Fig. 3). $\mathrm{EC}_{50}$ values for outward currents were $16 \mu \mathrm{M}\left(\mathrm{pH}_{\mathrm{i}} 7.2\right)$ and $15 \mu \mathrm{M}\left(\mathrm{pH}_{\mathrm{i}} 6.0\right)$ (Fig.

234 3D), and for inward currents were $21 \mu \mathrm{M}\left(\mathrm{pH}_{\mathrm{i}}\right.$ 7.2) and $26 \mu \mathrm{M}\left(\mathrm{pH}_{\mathrm{i}}\right.$ 6.0) (Fig. 3F). All

235 concentration-dependent curves plateaued after $50 \mu \mathrm{M}$ PS stimulations (Fig. 3). We

236 observed a downward shift of the outward current ratio curve in response to low $\mathrm{pH}$ (Fig.

237 3C). However, when currents were normalized to the maximum TRPM3 activation by 500

$238 \mu \mathrm{M}$ PS, the outward current curve did not deviate in response to low $\mathrm{pH}$ (Fig. 3D). These

239 results indicate that higher proton concentration inside the cell reduces TRPM3 maximal

240 activation potential at any given PS concentration but does not affect PS concentration-

241 dependent activation of TRPM3. The PS concentration-dependent curve of TRPM3 inward

242 currents did not show any change in response to low $\mathrm{pH}_{\mathrm{i}}$ (Fig. 3, E and F). In summary,

243 these data suggest that intracellular protons do not compete with PS for binding sites.

245 TRPM3 inhibition by protons can be reversed by increasing $\mathbf{p H}_{\mathbf{i}}$

246 Extracellular application of $\mathrm{NH}_{4} \mathrm{Cl}$ produces a rise in $\mathrm{pH}_{\mathrm{i}}$ resulting from an influx of $\mathrm{NH}_{3}$.

$247 \mathrm{NH}_{3}$ binds intracellular protons and causes alkalization inside the cells (Jacobs 1922;

248 Warburg 1922). We observed that protons blocked TRPM3 from the cytoplasmic side,

249 thus we tested whether raising $\mathrm{pH}_{\mathrm{i}}$ by applying $\mathrm{NH}_{4} \mathrm{Cl}$ could rescue the TRPM3 current.

250 We perfused the cells with solutions where part of $\mathrm{NaCl}$ was replaced by an equal amount

251 of $\mathrm{NH}_{4} \mathrm{Cl}$ (see experimental procedures), to test whether increasing $\mathrm{pH}_{\mathrm{i}}$ while keeping 252 extracellular $\mathrm{pH}$ the same can reverse the blocking effects of protons on TRPM3. As shown

253 in Fig. 4, A and B, 30mM NH $4 \mathrm{Cl}$ increased recorded TRPM3 currents significantly. We 
254 attribute this increase to the influx of $\mathrm{NH}_{3}$ into the cell and removing bound protons from

255 the TRPM3 cytoplasmic side. Overall, this result substantiates our finding that TRPM3 is

256 blocked by protons binding to an intracellular site. Different concentrations of $\mathrm{NH}_{4} \mathrm{Cl}$ were

257 applied to the same cell, and all $\mathrm{NH}_{4} \mathrm{Cl}$ applications change intracellular $\mathrm{pH}$. To confirm

258 that every TRPM3 stimulation starts at the same initial $\mathrm{pH}_{\mathrm{i}}$, we allowed adequate washing

259 time between two consecutive $\mathrm{NH}_{4} \mathrm{Cl}+\mathrm{PS}$ applications.

260 Subsequently, we wanted to test whether external $\mathrm{NH}_{4} \mathrm{Cl}$ exhibits a concentration

261 dependent rescuing effect on TRPM3 activity or not. We perfused hTRPM3-GFP

262 overexpressed HEK-293 cells with modified Tyrode solutions containing different

263 concentrations of $\mathrm{NH}_{4} \mathrm{Cl}(1-60 \mathrm{mM}) . \mathrm{Na}^{+}$concentrations in all solutions were kept the

264 same, and osmolarities were adjusted to $300 \pm 10 \mathrm{mOSM}$ with Mannitol. We observed a

265 5-fold increase in TRPM3 activity at only $3 \mathrm{mM}\left(\mathrm{NH}_{4} \mathrm{Cl}\right)$ concentration. Even $1 \mathrm{mM}$

$266 \mathrm{NH}_{4} \mathrm{Cl}$ rescued some TRPM3 activity $(\mathrm{p}<0.05)$. $\mathrm{NH}_{4} \mathrm{Cl}$ concentrations higher than $3 \mathrm{mM}$

267 had higher impact on TRPM3 activity than $3 \mathrm{mM} \mathrm{NH} 4 \mathrm{Cl}$. Although, when compared with

$2683 \mathrm{mM} \mathrm{NH} 4 \mathrm{Cl}$, some of these higher concentrations showed significant increase in TRPM3

269 activity, there were no substantial increase in TRPM3 activity by further increase in $\mathrm{NH}_{4} \mathrm{Cl}$

270 concentration. This data indicates that TRPM3 activity is highly sensitive to intracellular

$271 \mathrm{pH}$ changes, at least at the intracellular $\mathrm{pHs}$ over 6.0. It is noteworthy that we did not

272 measure exact $\mathrm{pH}_{\mathrm{i}}$ changes following external $\mathrm{NH}_{4} \mathrm{Cl}$ applications, so the $\mathrm{pH}_{\mathrm{i}}$ differences,

273 before and after $\mathrm{NH}_{4} \mathrm{Cl}$ applications, are unknown here. However, these experiments still

274 substantiate our claim that TRPM3 activity is highly sensitive to intracellular $\mathrm{pH}$ changes,

275 at least at physiological $\mathrm{pH}_{\mathrm{i}}$ ranges $\left(\mathrm{pH}_{\mathrm{i}} 6.0\right.$ to 8.0). In this experiment, TRPM3 current

276 recordings from each cell spanned over 20 minutes period. To confirm that subsequent 
277 application of $\mathrm{NH}_{4} \mathrm{Cl}$ and PS for a long time does not affect TRPM3 activity, we also tested

278 individual cells with only one exposure to $\mathrm{NH}_{4} \mathrm{Cl}$, at different concentrations. The results

279 of these experiments are summarized in Supplementary Fig. 1 (sFig. 1). When compared

280 with TRPM3 currents from our earlier experiments (Fig. 4, D), where the same cells were

281 perfused with different concentrations of $\mathrm{NH}_{4} \mathrm{Cl}$, individual cells did not show a difference

282 (sFig. 1B). We also observed a higher increase in inward current than corresponding the

283 outward current (Fig. 4, I). The ratio of inward current to outward current increased from

2840.13 at $1 \mathrm{mM} \mathrm{NH}_{4} \mathrm{Cl}$ to 0.54 at $60 \mathrm{mM} \mathrm{NH}_{4} \mathrm{Cl}$. This increase was consistent with the result

285 obtained from individual cells (sFig. 1).

\section{TRPM3 is potentially permeable to protons}

288 For a better understanding of the proton inhibition of TRPM3, we hypothesized that 289 protons permeate through TRPM3 when it is activated by PS. The lipid bilayer (e.g. cell

290 membrane) presents a strong barrier for the transport of charged ions through eukaryotic

291 cell membranes. Although the permeability of protons is higher than other monovalent

292 cations, which can partially be explained by the presence of transient water wires or long-

293 lived hydrophilic pores (Tepper and Voth 2005), it is unlikely that these mechanisms can

294 transport sufficient protons across the membrane to have a direct impact on an

295 overexpressed protein, unless protons are passing through the overexpressed ion-channel

296 itself. We thus examined whether protons can permeate through TRPM3. We recorded

297 TRPM3 inward current in HEK-293 cells, overexpressing hTRPM3-GFP, by holding the 298 membrane at $-100 \mathrm{mV}$ and applying PS and low $\mathrm{pH}$ solutions from the outside. We 299 maintained $\mathrm{pH}_{\mathrm{i}}$ at 7.6 to provide a higher concentration gradient for protons. All cations 
except protons were removed using NMDG in external and internal solutions. PS, along with NMDG pH 5.5 extracellular solution, produced a small transient inward current in

302 TRPM3 transfected HEK-293 cells (Fig. 5). Indeed, the amplitude of this current is 303 significantly lower than TRPM3 currents observed in our whole-cell recordings. This is 304 because in this experiment, all cations have been removed besides a limited amount of $\mathrm{H}^{+}$. 305 extracellular and intracellular proton concentrations was $3.2 \times 10^{-3} \mathrm{mM}(\mathrm{pH} 5.5)$ and 2.5 $306 \times 10^{-5} \mathrm{mM}(\mathrm{pH}$ 7.6) respectively. These concentrations represent the total cation 307 concentrations of these solutions, which are several orders of magnitude lower than the 308 total cation concentrations of our modified Tyrode solutions. In addition, extracellular $\mathrm{pH}$ 3095.5 blocks about $60 \%$ of TRPM3 currents. However, to provide a reasonable proton 310 gradient across the cell membrane, it is critical to conduct this experiment at a low 311 extracellular $\mathrm{pH}$. Since, there were no other cation involved, although low in amplitude, 312 this current suggests passage of proton through TRPM3 channel. In addition, the proton 313 current is transient is because of the intracellular inhibitory effects of $\mathrm{H}^{+}$on TRPM3 after 314 its permeation. Mock transfected cells did not produce any inward current in response to 315 PS (Data not shown). This evidence indicates that TRPM3 is potentially permeable to 316 proton.

\section{The inhibition of intracellular $\mathrm{Ca}^{2+}$ on TRPM3 is pH independent}

319 TRPM3 displays higher permeability for divalent cations than monovalent cations. For the 320 splice variant TRPM3 $\alpha 2,24 \%$ of total TRPM3 current is expected to result from $\mathrm{Ca}^{2+}$ 321 (Przibilla et al. 2018), suggesting a large increase in $\left[\mathrm{Ca}^{2+}\right]$ i following TRPM3 activation. 322 Multiple studies verified this effect showing an increase in $\left[\mathrm{Ca}^{2+}\right]_{i}$ in a micromolar range 
323 following TRPM3 activation (Vriens et al. 2011; Straub et al. 2013; Przibilla et al. 2018).

324 A recent study demonstrated that an increase in $\left[\mathrm{Ca}^{2+}\right] \mathrm{i}$, independent of TRPM3 activity, 325 inhibits TRPM3 in a calmodulin-dependent manner (Przibilla et al. 2018). This suggests a

326 potential negative feedback mechanism that regulates a high increase in $\left[\mathrm{Ca}^{2+}\right]$ i resulting

327 from TRPM3 activation. Studies conducted by others enlist $\left[\mathrm{Ca}^{2+}\right]$ i as a regulator of

328 TRPM3 activity. In our study, we found that intracellular proton blocks TRPM3 as well..

329 Hence, we asked the question, how do these two regulatory mechanisms interact with each

330 other? To find the effect of $\left[\mathrm{Ca}^{2+}\right]$ i on the concentration-dependent inhibition of TRPM3 by

331 protons, we tested TRPM3 activity in two different $\left[\mathrm{Ca}^{2+}\right]_{i}$ conditions, while providing a

332 wide range of $\mathrm{pH}_{\mathrm{i}}$, using whole-cell patch clamp of TRPM3 transfected cells. In addition

333 to the inhibition of TRPM3 current by $\left[\mathrm{Ca}^{2+}\right]_{i}$ observed by J. Przibilla et al., we observed

334 an additional delayed inhibition of TRPM3 current by $\mathrm{Ca}^{2+}$. For example, under $1 \mu \mathrm{M}$

$335\left[\mathrm{Ca}^{2+}\right]$, recorded current showed a further inhibition after initial activation and the residual

336 current amplitudes were less than $50 \%$ of the initial activation (Fig 6, B and C). Low [Ca $\left.{ }^{2+}\right] \mathrm{i}$

$337(<10 \mathrm{nM})$ did not show a delayed inhibition of TRPM3 current (Fig. 6A). $\mathrm{pH}_{\mathrm{i}}$

338 concentration-dependence of TRPM3 was not affected by $\left[\mathrm{Ca}^{2+}\right] \mathrm{i}$, as they showed similar

$339 \mathrm{pH}_{50}$ Values $(7.0 \pm 0.1,7.1 \pm 0.1,7.2 \pm 0.5)$ for low $\left[\mathrm{Ca}^{2+}\right]$, high $\mathrm{Ca}^{2+}$ initial and high $\mathrm{Ca}^{2+}$

340 delayed current intensities (Fig. 6E). It is noteworthy that, despite having similar $\mathrm{pH}_{50}$

341 values, TRPM3 outward current densities were significantly decreased in high $\left[\mathrm{Ca}^{2+}\right] \mathrm{i}$

342 conditions (Fig. 6E). To investigate if protons affected the percentage of current inhibited

343 in delayed current intensities compared with the initial current intensities, we analyzed the

344 ratio of delayed to initial current intensities in different $\mathrm{pH}_{\mathrm{i}}$ at high $\left[\mathrm{Ca}^{2+}\right]_{\mathrm{i}}$ concentration.

345 We did not observe any significant difference between the ratios resulting from different 
$346 \mathrm{pH}$ (Fig. 6F). Overall, these results indicate that, although $\left[\mathrm{Ca}^{2+}\right]_{\mathrm{i}}$ inhibits TRPM3, it does

347 not affect the regulation of TRPM3 by intracellular protons.

\section{Molecular mechanism underlying TRPM3 inhibition by protons}

350 Glutamate, aspartate, histidine, and lysine residues are potential proton acceptors, 351 especially glutamate and aspartate, which present negative charges (Zhou and Pang 2018).

352 To identify the amino acid residues of TRPM3 accountable for its sensitivity to $\mathrm{pH}_{\mathrm{i}}$, we 353 prepared hTRPM3-GFP mutant plasmids having mutations in the pore region. We selected

354 all eight glutamate and aspartate amino acids, in the vestibule of the loop between S5 and 355 S6 transmembrane domains (Fig. 7A). These eight residues were either a glutamate and 356 aspartate amino acid, and they were mutated to glutamine. We created two double mutants 357 (E1034Q - E1035Q, E1072Q - D1073Q) and six single mutants (E1055Q, D1059Q, 358 D1062Q, E1069Q, E1072Q, and D1073Q). We expressed these mutants in HEK-293 cells 359 and recorded elicited currents in response to PS, while perfusing with physiological and 360 low pH external solutions (Fig. 7B). Except for E1055Q, which resulted in a non-functional 361 ion-channel, all other mutants exhibited identical I-V relation to WT-hTRPM3, although 362 most of the mutants showed markedly reduced current amplitudes (Fig. 7B). We perfused 363 cells expressing these mutants with external solutions of $\mathrm{pH} 7.4$ and $\mathrm{pH} 5.5$. The $\mathrm{pH}$ of 5.5 364 was selected as representative of low $\mathrm{pH}$ external solutions because at this $\mathrm{pH}$, WT-TRPM3 365 currents were blocked significantly yet sufficient activity was maintained for analysis. We 366 compared the percent decrease in TRPM3 current from $\mathrm{pH}_{\mathrm{o}} 7.4$ to $\mathrm{pH}_{\mathrm{o}} 5.5$ for all the 367 mutants and WT-TRPM3 (Fig. 7C). The double mutant (E1034Q - E1035Q), E1069Q, and 368 E1072Q showed similar sensitivity to protons when compared with the WT-TRPM3. 
369 Mutants D1059Q and D1062Q were found to be more sensitive to protons, as the reduction

370 of whole-cell current due to low $\mathrm{pH}_{\mathrm{o}}$ was increased to $93.9 \%$ and $84.1 \%$ in D1059Q and

371 D1062Q, respectively, compared to 56.5\% observed in WT-TRPM3. Mutant D1073Q

372 showed significantly less sensitivity towards protons, as $\mathrm{pH}_{\mathrm{o}} 5.5$ reduced its current

373 amplitude only by $25 \%$. As summarized in Fig. 7C, these results establish the amino acid

374 residues D1059Q, D1062Q and D1073Q as some of the key determinants of protons

375 sensitivity in TRPM3. Although it is unclear at this moment why mutating these residues

376 produce variable effects (increased or decreased proton sensitivity), these data suggested

377 that the pore vestibule of TRPM3 is critical for the $\mathrm{pH}$ sensitivity. Further studies are

378 required to delineate the underlying mechanism of these variable effects.

\section{Discussion}

381 We demonstrated for the first time that TRPM3 is a proton-permeable channel regulated

382 by both extracellular and intracellular acidic conditions. Our experiments suggest a direct 383 interaction of intracellular protons with the cytoplasmic side of TRPM3 to induce a 384 blocking effect, whereas extracellular protons permeate through the ion-channel first to 385 block it from the intracellular side. We also demonstrated that the blocking effect of the 386 intracellular protons could be reversed by decreasing intracellular protons concentrations, 387 which indicates a reversible binding of protons to the intracellular amino acid residues. We 388 identified an internal residue responsible for protons sensitivity of TRPM3. Finally, we 389 demonstrated that low internal $\mathrm{pH}$ produces a downward shift of PS concentration390 dependent activation of TRPM3 by reducing the amplitude of TRPM3-mediated currents 
391 at any given $\mathrm{pH}$. Overall, we report evidence for the regulatory role of protons on TRPM3

392 activation and the molecular mechanism responsible for it.

393

\section{General characteristics of TRPM3}

395 TRPM3 is a heat-sensitive ion channel, which is expressed in a somatosensory neuron 396 where its role as a noxious heat sensor has been established (Vriens et al. 2011;

397 Vandewauw et al. 2018). Activation of pancreatic TRPM3 increases glucose-induced 398 insulin release (Wagner et al. 2008). These data indicate the existence of multiple TRPM3 399 regulatory molecules. Indeed, cytosolic phosphatidylinositol bisphosphates (PIPs) and 400 ATP have a stimulatory effect on TRPM3. Activation of phospholipase C-coupled 401 muscarinic acetylcholine receptors inhibit recombinant and endogenous TRPM3 (Toth et 402 al. 2015). Calmodulin binds to multiple sites of TRPM3 in $\mathrm{Ca}^{2+}$-dependent manner, and 403 both intracellular calmodulin and $\mathrm{Ca}^{2+}$ inhibits TRPM3 (Holakovska et al. 2012; Przibilla 404 et al. 2018). Here we report the modulatory role of protons on TRPM3. Reversible 405 inhibition of TRPM3 by protons indicates that acidic $\mathrm{pH}$ may serve as a negative feedback 406 mechanism to regulate TRPM3 activity in physiological/pathological conditions.

408 Regulations of pH on TRP channels

409 Acidification has modulatory effects on variety of ion channels (discussed in the 410 introduction) including TRP channels. Extracellular acidic pH modulates TRPV1 channel

411 gating (Jordt, Tominaga, and Julius 2000; Ryu, Liu, and Qin 2003), stimulates TRPC4 and

412 TRPC5, but inhibits TRPC6 (Semtner et al. 2007), TRPM5 (Liu, Zhang, and Liman 2005), 413 and TRPV5 (Yeh et al. 2003), and potentiates TRPM6 and TRPM7 inward currents (Jiang, 
414 Li, and Yue 2005; Li, Jiang, and Yue 2006; Li et al. 2007). Intracellular protons inhibit

415 TRPM7 (Kozak et al. 2005), and block TRPM8 (Andersson, Chase, and Bevan 2004). Here

416 we demonstrate that PS-induced TRPM3 outward and inward currents both are inhibited

417 by protons. Although both intracellular and extracellular acidic conditions inhibit TRPM3,

418 there are differences between internal and external proton-induced inhibition. Extracellular

419 protons cannot inhibit TRPM3 until $\mathrm{pH}$ reaches below 6.0, but $\mathrm{pH}_{\mathrm{i}}$ has a $\mathrm{pH}_{50}$ value of 6.9.

420 We demonstrated a very sharp inhibition by protons at an external $\mathrm{pH}$ below 6.0; this

421 inhibition did not follow a typical concentration-response relationship. Whereas internal

422 protons efficiently blocked TRPM3 current and showed a concentration-response

423 relationship. These results suggest that protons are not competing with PS for the same

424 binding site of TRPM3, and indicated that TRPM3 may contain proton-binding sites in the

425 cytoplasmic domains. It is plausible that an increase in extracellular proton's concentration

426 causes protons influx through TRPM3 that enables protons to bind to its internal binding

427 site to inhibit TRPM3. To rule out the effects of proton-activated endogenous chloride

428 currents, we conducted all whole-cell recordings under very low intracellular and

429 extracellular $\mathrm{Cl}^{-}$concentrations. Indeed, our external and internal solutions contained 8

$430 \mathrm{mM} \mathrm{Cl}^{-}$, but this concentration of protons is not capable of activating endogenous anions

431 channels of HEK293 cells (Lambert and Oberwinkler 2005).

\section{Mechanisms of effects of protons on TRPM3}

434 It appeared that extracellular $\mathrm{pH}(<6.0)$ strongly blocks TRPM3 activities, which would 435 indicate TRPM3 is regulated by extracellular acidic $\mathrm{pH}$ directly. However, the lack of $\mathrm{pH}$ 436 concentration-dependent activity did not support this hypothesis. These findings led us to 
437 the conclusion that protons do not have extracellular binding sites, at least under the

438 activations of PS. Reduced intracellular $\mathrm{pH}$ appeared to have clear $\mathrm{pH}$ concentration-

439 dependent effects on TRPM3, which begs the question: how might external protons affect

440 TRPM3 gating properties? The cell membrane must have a mechanism for the proton

441 permeation and thus change the intracellular $\mathrm{pH}$. It is possible that protons cross the

442 TRPM3 while it is open, although we cannot exclude the possibility that protons may

443 permeate the cell membrane directly.

444 Our data suggests that protons directly cross TRPM3 when it is activated by PS.

445 Consistently, no proton current was found without activating TRPM3, supporting the

446 conclusion that TRPM3 is potentially permeable to protons. We also studied the regulation

447 of TRPM3 by $\mathrm{Ca}^{2+}$. Previous studies have shown that TRPM3 is a $\mathrm{Ca}^{2+}$ permeable ion

448 channel (Grimm et al. 2003; Lee et al. 2003). TRPM3 channel activity strongly depends

449 on intracellular $\mathrm{Ca}^{2+}$ (Przibilla et al. 2018). Along with the inhibition of TRPM3 current

450 amplitude, we also found that $\mathrm{Ca}^{2+}$ accelerates the decay time of TRPM3. Increased $\left[\mathrm{Ca}^{2+}\right] \mathrm{i}$

451 from minimum to $1 \mu \mathrm{M}$ significantly reduces the plateau of the current. In general, $\left[\mathrm{Ca}^{2+}\right] \mathrm{i}$

452 is a key regulator to modulate the TRPM3 gating - we hoped to visualize the interaction

453 between $\left[\mathrm{Ca}^{2+}\right]$ i and protons. However, high $\left[\mathrm{Ca}^{2+}\right]_{\mathrm{i}}$ did not change the $\mathrm{pH} 50$ of the effects

454 of intracellular protons on TRPM3 (Fig. 6). Vice versa, decreased $\left[\mathrm{H}^{+}\right]_{\mathrm{i}}$ did not affect the

$455 \mathrm{Ca}^{2+}$ inhibition on TRPM3 (Fig. 6). Therefore, it appears unlikely that protons can inhibit

456 TRPM3 channel activities by competing with $\left[\mathrm{Ca}^{2+}\right]$ i for a binding site on the cytoplasmic

457 side.

458 To determine the molecular mechanism by which intracellular protons inhibit

459 TRPM3, we mutated all the titratable residues in the pore region between S5 and S6 to 
460 determine which sites are responsible for $\mathrm{pH}_{\mathrm{i}}$ sensitivity. Among most of the mutations of

461 Asp and Glu residues, three residues-D1059, D1062 and D1073-which we predicted to

462 locate in the inner vestibule in the pore region, strongly change the proton sensitivities. We

463 conclude these residues in the pore region could be the proton binding sites. Of course, we

464 should not exclude any other intracellular binding sites. For example, $\mathrm{C}$ terminus of the

465 S4-S5 linker is thought to be critical for changing TRP channel's $\mathrm{pH}_{\mathrm{i}}$ sensitivity (Du, Xie,

466 and Yue 2009). Although, how intracellular protons change TRPM3 gating properties

467 through these residues is still unknown, it will be of interest to investigate whether acidic

468 intracellular $\mathrm{pH}$ alters intracellular signaling pathways in future studies. It will also be of

469 interest to investigate other potential proton binding sites that might interact with $\left[\mathrm{Ca}^{2+}\right]_{\mathrm{i}}$

470 near the intracellular mouth and act as the $\left[\mathrm{Ca}^{2+}\right]$ i-activating site to regulate $\left[\mathrm{Ca}^{2+}\right] \mathrm{i}$

471 mediated TRPM3 activation. Further investigation is required to test this hypothesis.

472

\section{Conclusion}

474 Our findings suggest that cellular acidification serves as a negative or protective feedback

475 mechanism to limit TRPM3 activities. Although the development of intracellular acidosis

476 has not been well established, metabolic acidosis is a relatively common condition that

477 causes $\mathrm{pH}_{\mathrm{i}}$ to fall (Salameh, Ruffin, and Boron 2014). Some reports suggest that during

478 metabolic acidosis, insulin secretion is depressed (Mak 1998; Bigner et al. 1996). Thus, it

479 is possible that a low $\mathrm{pH}$-mediated dampening of TRPM3 activity might contribute to the

480 decreased insulin secretion observed in metabolic acidosis. If true, then modulating

481 TRPM3 activity might be a potential future clinical application in treating acidosis induced

482 pancreatic disorders. 
484 dependent inhibition of the TRPM3 channels. Asp1073 residue in the inner vestibule of the

485 channel pore is critical in modulating this inhibition. Given the physiological significance

486 of TRPM3 in numerous cells, including pancreatic beta cells and sensory neurons,

487 understanding TRPM3 gating by protons may generate new physiological and/or 488 pathological insights.

490 Acknowledgement

491 We thank Dr. C. Harteneck for providing the TRPM3 construct. We thank Dr. Lixia Yue

492 for her suggestions and comments. We thank Dr. Boren Lin, Erin Koffman, Tyler Ortyl,

493 Farzaneh Naghavi, and Kritika Singh for their comments. J.D. is supported by the National

494 Institutes of Mental Health (5R01 MH1 13986). LRR is supported by the National Institutes

495 of Health (R00HL119560, OT2OD023854, OT2OD026582)

496

497 Conflict of Interest

498 The authors declare no conflict of interest.

\section{Author Contributions}

501 J.D. conceived and supervised the project. J.D., MZ.HS. and L.X. designed the experiments 502 with input from Y.S.L. and L.R.R. MZ.HS. and L.X. did most of the patch-clamp 503 experiments. Y.S.L. and L.R.R. performed molecular biology experiments and oversaw the 504 mutagenesis of TRPM3. MZ.HS. and J.D. drafted the manuscript with input from all 505 authors contributed to finalizing the manuscript. 
507 Abbreviations

508 TRP: Transient Receptor Potential; TRPM: Melastatin-like TRP channels; GFP: Green

509 Fluorescent Protein; NMDG: N-methyl-D-glucamine; PS: Pregnenolone Sulfate;

$510 \mathrm{pH}_{\mathrm{o}}:$ Extracellular $\mathrm{pH} ; \mathrm{pH}_{\mathrm{i}}$ : Intracellular $\mathrm{pH}$; AP-1: Activator Protein-1; Egr-1: Early

511 Growth Response protein 1; CRE: cAMP response element; K2p: Two-pore domain $\mathrm{K}^{+}$

512 channels: TWIK: Tandem of pore domains in Weak Inward rectifier $\mathrm{K}^{+}$channels; TASK:

513 TWIK-related Acid-Sensitive $\mathrm{K}^{+}$channels; Kir: Inward rectifier $\mathrm{K}^{+}$channel; TREK:

514 TWIK-RElated $\mathrm{K}^{+}$channels; TRESK: TWIK-RElated spinal cord $\mathrm{K}^{+}$channels; TALK:

515 TWIK-related ALkaline $\mathrm{pH}$-activated $\mathrm{K}^{+}$channels; ATP: Adenosine TriPhosphate;

516 PKD2L1: Polycystic Kidney Disease 2-Like ion channel-1; CGRP: Calcitonin Gene-

517 Related Protein.

\section{References}

Alonso-Carbajo, L., Y. A. Alpizar, J. B. Startek, J. R. Lopez-Lopez, M. T. Perez-Garcia, and K. Talavera. 2019. 'Activation of the cation channel TRPM3 in perivascular nerves induces vasodilation of resistance arteries', J Mol Cell Cardiol, 129: 21930 .

Andersson, D. A., H. W. Chase, and S. Bevan. 2004. 'TRPM8 activation by menthol, icilin, and cold is differentially modulated by intracellular $\mathrm{pH}^{\prime}, J$ Neurosci, 24 : 5364-9.

Bennett, Thomas M., Donna S. Mackay, Carla J. Siegfried, and Alan Shiels. 2014. 'Mutation of the melastatin-related cation channel, TRPM3, underlies inherited cataract and glaucoma', PLoS One, 9: e104000-e00.

Bigner, D. R., J. P. Goff, M. A. Faust, J. L. Burton, H. D. Tyler, and R. L. Horst. 1996. 'Acidosis effects on insulin response during glucose tolerance tests in Jersey cows', J Dairy Sci, 79: 2182-8.

Brauchi, S., and P. Orio. 2011. 'Voltage sensing in thermo-TRP channels', Adv Exp Med Biol, 704: 517-30. 
Caterina, M. J., M. A. Schumacher, M. Tominaga, T. A. Rosen, J. D. Levine, and D. Julius. 1997. 'The capsaicin receptor: a heat-activated ion channel in the pain pathway', Nature, 389: 816-24.

Chandrashekar, J., M. A. Hoon, N. J. Ryba, and C. S. Zuker. 2006. 'The receptors and cells for mammalian taste', Nature, 444: 288-94.

Ciurtin, C., Y. Majeed, J. Naylor, P. Sukumar, A. A. English, P. Emery, and D. J. Beech. 2010. 'TRPM3 channel stimulated by pregnenolone sulphate in synovial fibroblasts and negatively coupled to hyaluronan', BMC Musculoskelet Disord, 11: 111.

Clapham, D. E. 2003. 'TRP channels as cellular sensors', Nature, 426: 517-24.

Du, Jianyang, Jia Xie, and Lixia Yue. 2009. 'Modulation of TRPM2 by acidic $\mathrm{pH}$ and the underlying mechanisms for $\mathrm{pH}$ sensitivity', The Journal of general physiology, 134: 471-88.

Dyment, David A, Paulien A Terhal, Cecilie F Rustad, Kristian Tveten, Christopher Griffith, Parul Jayakar, Marwan Shinawi, Sara Ellingwood, Rosemarie Smith, and Koen van Gassen. 2019. 'De novo substitutions of TRPM3 cause intellectual disability and epilepsy', European Journal of Human Genetics, 27: 1611-18.

Everaerts, W., M. Gees, Y. A. Alpizar, R. Farre, C. Leten, A. Apetrei, I. Dewachter, F. van Leuven, R. Vennekens, D. De Ridder, B. Nilius, T. Voets, and K. Talavera. 2011. 'The capsaicin receptor TRPV1 is a crucial mediator of the noxious effects of mustard oil', Curr Biol, 21: 316-21.

Gerdes, J. M., Y. Liu, N. A. Zaghloul, C. C. Leitch, S. S. Lawson, M. Kato, P. A. Beachy, P. L. Beales, G. N. DeMartino, S. Fisher, J. L. Badano, and N. Katsanis. 2007. 'Disruption of the basal body compromises proteasomal function and perturbs intracellular Wnt response', Nat Genet, 39: 1350-60.

Grimm, C., R. Kraft, S. Sauerbruch, G. Schultz, and C. Harteneck. 2003. 'Molecular and functional characterization of the melastatin-related cation channel TRPM3', $J$ Biol Chem, 278: 21493-501.

Hardie, R. C. 2014. 'Photosensitive TRPs', Handb Exp Pharmacol, 223: 795-826.

Hardie, R. C., and K. Franze. 2012. 'Photomechanical responses in Drosophila photoreceptors', Science, 338: 260-3.

Held, Katharina, Marie Mulier, Nele Van Ranst, Yang Ge, Thomas Voets, Yu Tian Wang, and Joris Vriens. 2020. 'TRPM3 Inhibits Synaptic Transmission and Plasticity in the Hippocampus', Biophysical Journal, 118: 21 a.

Holakovska, B., L. Grycova, M. Jirku, M. Sulc, L. Bumba, and J. Teisinger. 2012. 'Calmodulin and S100A1 protein interact with N terminus of TRPM3 channel', $J$ Biol Chem, 287: 16645-55.

Holzer, Peter. 2009. 'Acid-sensitive ion channels and receptors', Handbook of experimental pharmacology: 283-332.

Huang, Angela L., Xiaoke Chen, Mark A. Hoon, Jayaram Chandrashekar, Wei Guo, Dimitri Tränkner, Nicholas J. P. Ryba, and Charles S. Zuker. 2006. 'The cells and logic for mammalian sour taste detection', Nature, 442: 934-38.

Jacobs, M. H. 1922. 'The influence of ammonium salts on cell reaction', J Gen Physiol, 5: 181-8.

Jiang, J., M. Li, and L. Yue. 2005. 'Potentiation of TRPM7 inward currents by protons', $J$ Gen Physiol, 126: 137-50. 
Jordt, S. E., M. Tominaga, and D. Julius. 2000. 'Acid potentiation of the capsaicin receptor determined by a key extracellular site', Proc Natl Acad Sci U S A, 97: 8134-9.

Kozak, J. A., M. Matsushita, A. C. Nairn, and M. D. Cahalan. 2005. 'Charge screening by internal $\mathrm{pH}$ and polyvalent cations as a mechanism for activation, inhibition, and rundown of TRPM7/MIC channels', J Gen Physiol, 126: 499-514.

Lambert, S., and J. Oberwinkler. 2005. 'Characterization of a proton-activated, outwardly rectifying anion channel', J Physiol, 567: 191-213.

Lee, N., J. Chen, L. Sun, S. Wu, K. R. Gray, A. Rich, M. Huang, J. H. Lin, J. N. Feder, E. B. Janovitz, P. C. Levesque, and M. A. Blanar. 2003. 'Expression and characterization of human transient receptor potential melastatin 3 (hTRPM3)', $J$ Biol Chem, 278: 20890-7.

Lesch, A., S. Rubil, and G. Thiel. 2014. 'Activation and inhibition of transient receptor potential TRPM3-induced gene transcription', Br J Pharmacol, 171: 2645-58.

Li, M., J. Du, J. Jiang, W. Ratzan, L. T. Su, L. W. Runnels, and L. Yue. 2007. 'Molecular determinants of $\mathrm{Mg} 2+$ and $\mathrm{Ca} 2+$ permeability and $\mathrm{pH}$ sensitivity in TRPM6 and TRPM7', J Biol Chem, 282: 25817-30.

Li, M., J. Jiang, and L. Yue. 2006. 'Functional characterization of homo- and heteromeric channel kinases TRPM6 and TRPM7', J Gen Physiol, 127: 525-37.

Liedtke, W., and J. M. Friedman. 2003. 'Abnormal osmotic regulation in trpv4-/- mice', Proc Natl Acad Sci U S A, 100: 13698-703.

Liu, D., Z. Zhang, and E. R. Liman. 2005. 'Extracellular acid block and acid-enhanced inactivation of the $\mathrm{Ca} 2+$-activated cation channel TRPM5 involve residues in the S3-S4 and S5-S6 extracellular domains', J Biol Chem, 280: 20691-9.

Mak, R. H. 1998. 'Effect of metabolic acidosis on insulin action and secretion in uremia', Kidney Int, 54: 603-7.

Maroto, R., A. Raso, T. G. Wood, A. Kurosky, B. Martinac, and O. P. Hamill. 2005. 'TRPC1 forms the stretch-activated cation channel in vertebrate cells', Nat Cell Biol, 7: 179-85.

McKemy, D. D., W. M. Neuhausser, and D. Julius. 2002. 'Identification of a cold receptor reveals a general role for TRP channels in thermosensation', Nature, 416: 52-8.

Minke, B. 1977. 'Drosophila mutant with a transducer defect', Biophys Struct Mech, 3: 59-64.

Montell, C., K. Jones, E. Hafen, and G. Rubin. 1985. 'Rescue of the Drosophila phototransduction mutation trp by germline transformation', Science, 230: 1040-3.

Moran, M. M., and A. Szallasi. 2018. 'Targeting nociceptive transient receptor potential channels to treat chronic pain: current state of the field', Br J Pharmacol, 175: 2185-203.

Muller, I., O. G. Rossler, and G. Thiel. 2011. 'Pregnenolone sulfate activates basic region leucine zipper transcription factors in insulinoma cells: role of voltage-gated $\mathrm{Ca} 2+$ channels and transient receptor potential melastatin 3 channels', Mol Pharmacol, 80: 1179-89.

Naylor, J., J. Li, C. J. Milligan, F. Zeng, P. Sukumar, B. Hou, A. Sedo, N. Yuldasheva, Y. Majeed, D. Beri, S. Jiang, V. A. Seymour, L. McKeown, B. Kumar, C. Harteneck, D. O'Regan, S. B. Wheatcroft, M. T. Kearney, C. Jones, K. E. Porter, and D. J. 
628

629

630
Beech. 2010. 'Pregnenolone sulphate- and cholesterol-regulated TRPM3 channels coupled to vascular smooth muscle secretion and contraction', Circ Res, 106: 1507-15.

Oberwinkler, J., A. Lis, K. M. Giehl, V. Flockerzi, and S. E. Philipp. 2005. 'Alternative splicing switches the divalent cation selectivity of TRPM3 channels', $J$ Biol Chem, 280: 22540-8.

Oberwinkler, J., and S. E. Philipp. 2014. 'TRPM3', Handb Exp Pharmacol, 222: 427-59. Pan, Z., H. Yang, and P. S. Reinach. 2011. 'Transient receptor potential (TRP) gene superfamily encoding cation channels', Hum Genomics, 5: 108-16.

Przibilla, J., S. Dembla, O. Rizun, A. Lis, M. Jung, J. Oberwinkler, A. Beck, and S. E. Philipp. 2018. ' $\mathrm{Ca}(2+)$-dependent regulation and binding of calmodulin to multiple sites of Transient Receptor Potential Melastatin 3 (TRPM3) ion channels', Cell Calcium, 73: 40-52.

Quallo, T., N. Vastani, E. Horridge, C. Gentry, A. Parra, S. Moss, F. Viana, C. Belmonte, D. A. Andersson, and S. Bevan. 2015. 'TRPM8 is a neuronal osmosensor that regulates eye blinking in mice', Nat Commun, 6: 7150.

Ryu, S., B. Liu, and F. Qin. 2003. 'Low $\mathrm{pH}$ potentiates both capsaicin binding and channel gating of VR1 receptors', J Gen Physiol, 122: 45-61.

Salameh, A. I., V. A. Ruffin, and W. F. Boron. 2014. 'Effects of metabolic acidosis on intracellular $\mathrm{pH}$ responses in multiple cell types', Am J Physiol Regul Integr Comp Physiol, 307: R1413-27.

Semtner, M., M. Schaefer, O. Pinkenburg, and T. D. Plant. 2007. 'Potentiation of TRPC5 by protons', J Biol Chem, 282: 33868-78.

Smith, C. C., T. T. Gibbs, and D. H. Farb. 2014. 'Pregnenolone sulfate as a modulator of synaptic plasticity', Psychopharmacology (Berl), 231: 3537-56.

Straub, I., U. Krugel, F. Mohr, J. Teichert, O. Rizun, M. Konrad, J. Oberwinkler, and M. Schaefer. 2013. 'Flavanones that selectively inhibit TRPM3 attenuate thermal nociception in vivo', Mol Pharmacol, 84: 736-50.

Strotmann, R., C. Harteneck, K. Nunnenmacher, G. Schultz, and T. D. Plant. 2000. 'OTRPC4, a nonselective cation channel that confers sensitivity to extracellular osmolarity', Nat Cell Biol, 2: 695-702.

Sun, Y., L. Liu, Y. Ben-Shahar, J. S. Jacobs, D. F. Eberl, and M. J. Welsh. 2009. 'TRPA channels distinguish gravity sensing from hearing in Johnston's organ', Proc Natl Acad Sci U S A, 106: 13606-11.

Suzuki, M., A. Mizuno, K. Kodaira, and M. Imai. 2003. 'Impaired pressure sensation in mice lacking TRPV4', J Biol Chem, 278: 22664-8.

Tepper, H. L., and G. A. Voth. 2005. 'Protons may leak through pure lipid bilayers via a concerted mechanism', Biophys J, 88: 3095-108.

Toth, B. I., M. Konrad, D. Ghosh, F. Mohr, C. R. Halaszovich, M. G. Leitner, J. Vriens, J. Oberwinkler, and T. Voets. 2015. 'Regulation of the transient receptor potential channel TRPM3 by phosphoinositides', J Gen Physiol, 146: 51-63.

Uchida, K., N. Fukuta, J. Yamazaki, and M. Tominaga. 2019. 'Identification and classification of a new TRPM3 variant (gamma subtype)', J Physiol Sci, 69: 62334. 
672 Vandewauw, I., K. De Clercq, M. Mulier, K. Held, S. Pinto, N. Van Ranst, A. Segal, T.

673 Voet, R. Vennekens, K. Zimmermann, J. Vriens, and T. Voets. 2018. 'A TRP channel trio mediates acute noxious heat sensing', Nature, 555: 662-66. Vriens, and T. Voets. 2020. 'Functional expression and pharmacological modulation of TRPM3 in human sensory neurons', Br J Pharmacol.

Venkatachalam, Kartik, and Craig Montell. 2007. 'TRP channels', Annual review of biochemistry, 76: 387-417.

Vriens, J., G. Owsianik, T. Hofmann, S. E. Philipp, J. Stab, X. Chen, M. Benoit, F. Xue, A. Janssens, S. Kerselaers, J. Oberwinkler, R. Vennekens, T. Gudermann, B. Nilius, and T. Voets. 2011. 'TRPM3 is a nociceptor channel involved in the detection of noxious heat', Neuron, 70: 482-94.

Wagner, T. F., S. Loch, S. Lambert, I. Straub, S. Mannebach, I. Mathar, M. Dufer, A. Lis, V. Flockerzi, S. E. Philipp, and J. Oberwinkler. 2008. 'Transient receptor potential M3 channels are ionotropic steroid receptors in pancreatic beta cells', Nat Cell Biol, 10: 1421-30.

Warburg, E. J. 1922. 'Studies on Carbonic Acid Compounds and Hydrogen Ion Activities in Blood and Salt Solutions. A Contribution to the Theory of the Equation of Lawrence J. Henderson and K. A. Hasselbach: Introduction', Biochem J, 16: 1534.

Yeh, B. I., T. J. Sun, J. Z. Lee, H. H. Chen, and C. L. Huang. 2003. 'Mechanism and molecular determinant for regulation of rabbit transient receptor potential type 5 (TRPV5) channel by extracellular pH', J Biol Chem, 278: 51044-52.

Zamudio-Bulcock, P. A., J. Everett, C. Harteneck, and C. F. Valenzuela. 2011. 'Activation of steroid-sensitive TRPM3 channels potentiates glutamatergic transmission at cerebellar Purkinje neurons from developing rats', J Neurochem, 119: 474-85.

Zhou, Huan-Xiang, and Xiaodong Pang. 2018. 'Electrostatic Interactions in Protein Structure, Folding, Binding, and Condensation', Chemical reviews, 118: 1691741. 


\section{Figure legends}

Figure 1 Inhibitory effect of extracellular acidic $\mathrm{pH}$ on TRPM3 activation by PS. (a) Time course of TRPM3 currents elicited by voltage ramps ranging -100 to $+100 \mathrm{mV}$. Both inward and outward currents were completely and reversibly inhibited by $\mathrm{pH}_{\mathrm{o}}$ 4.5. $50 \mathrm{uM}$ PS was applied extracellularly and was washed with PS-free extracellular solution between subsequent PS application. Inward and outward currents were measured at -100 and $+100 \mathrm{mV}$, respectively. (b) Representative recording of TRPM3 current in (a) by ramp protocols ranging from -100 to +100 $\mathrm{mV}$ at the indicated $\mathrm{pH}_{\mathrm{o}}$. (c) Mean current amplitude of TRPM3 at the indicated $\mathrm{pH}_{\mathrm{o}}$ in (a) (mean \pm SEM; $\mathrm{n}=11, *$ indicates $\mathrm{p}<0.05$ by unpaired Student's t-test; "n.s." indicates not statistically significant). (d) Current amplitude at the indicated $\mathrm{pH}_{\mathrm{o}}$ normalized to the current amplitude at $\mathrm{pH}_{\mathrm{o}}$ 7.4 in (a). When compared with $\mathrm{pH}_{\mathrm{o}} 7.4, p$ value for $\mathrm{pH}_{\mathrm{o}} 7.0$ and 6.0 were 0.15 and 0.06 , respectively. Background electrical activity before application of PS are subtracted in all quantitative analysis. (e) Time course of TRPM3 currents elicited by voltage ramps ranging -100 to $+100 \mathrm{mV}$. PS was applied continuously while reducing extracellular $\mathrm{pH}$ without allowing any washing period between subsequent extracellular solution applications. (f) Representative recording of TRPM3 current in (e) by ramp protocols ranging from -100 to $+100 \mathrm{mV}$ at the indicated $\mathrm{pH}_{\mathrm{o}}$ ( $\mathrm{g}$ ) Mean current amplitude of TRPM3 at the indicated $\mathrm{pH}_{\mathrm{o}}$ in (E) (mean $\pm \mathrm{SEM}$; $\mathrm{n}$ $=7$, * indicates $\mathrm{p}<0.05$ by unpaired Student's t-test; "n.s." indicates not statistically significant).

(h) Current amplitude at the indicated $\mathrm{pH}_{\mathrm{o}}$ normalized to the current amplitude at $\mathrm{pH}_{\mathrm{o}}$ 7.4.

Figure 2 Intracellular acidification blocks TRPM3 activation by PS in a concentration-dependent manner. (a) Representative recordings and time courses (insert) of TRPM3 current by ramp 
protocols ranging from -100 to $+100 \mathrm{mV}$ at the indicated $\mathrm{pH}_{\mathrm{i}}$. PS was applied through the extracellular solution ( $\mathrm{pH}_{\mathrm{o}}$ 7.4) and different cells were exposed to different $\mathrm{pH}_{\mathrm{i}}$ while keeping that $\mathrm{pH}_{\mathrm{i}}$ constant. (b) Mean current amplitude of TRPM3 at the indicated $\mathrm{pH}_{\mathrm{i}}($ mean $\pm \mathrm{SEM}$; $\mathrm{n}=$ 8 - 14). (c and d) $\mathrm{pH}_{\mathrm{i}}$ concentration-dependence of TRPM3 activation by PS. $\mathrm{c}$ and $\mathrm{d}$ show outward and inward current, respectively, elicited by TRPM3 after extracellular PS application, by voltage ramp ranging -100 to $+100 \mathrm{mV}$. TRPM3 currents exerted at -100 and $+100 \mathrm{mV}$ were considered as inward and outward current, respectively, and were utilized for these plots. All currents were normalized to corresponding capacitance of the cell overexpressing hTRPM3GFP. Each data point is the mean of 8-14 cells with the error bar showing SEM, at the indicated $\mathrm{pH}_{\mathrm{i}}$. Inhibitory $\mathrm{pH}_{50}$ values were measured separately for outward $\left(\mathrm{pH}_{50}=6.9 \pm 0.11\right)$ and inward $\left(\mathrm{pH}_{50}=6.9 \pm 0.15\right)$ currents.

Figure 3 Concentration-response curve for PS-induced currents in hTRPM3, at the indicated intracellular $\mathrm{pH}$. (a) Time course of TRPM3 currents elicited by voltage ramps ranging -100 to $+100 \mathrm{mV}$. PS was applied extracellularly in increasing concentration sequence at concentrations of $0,0.1,1,10,20,50,100$ and $500 \mu \mathrm{M}$, with adequate washing period between subsequent PS applications. (b) Representative recording of TRPM3 current at the indicated PS concentration in (a). (c) Mean outward currents measured at $+100 \mathrm{mV}$ and normalized to corresponding capacitance of the cell, error bars showing SEM ( $n=7$ cells), plotted against logarithmic values of PS concentrations. (d) Outward current normalized to maximum concentration-response $(500 \mu \mathrm{M})$ of the same cell in (c). The $\mathrm{EC}_{50}$ values of PS for the outward currents are $16.4 \pm 1.1 \mu \mathrm{M}$ at $\mathrm{pH} 7.2$ and $15.8 \pm 1.1 \mu \mathrm{M}$ at $\mathrm{pH}$ 6.0. (e). Mean inward currents measured at $-100 \mathrm{mV}$ and normalized to corresponding capacitance of the cell, error bars showing SEM ( $\mathrm{n}=7$ cells), plotted against 
logarithmic values of PS concentrations. (f). Inward current normalized to maximum concentration-response $(500 \mu \mathrm{M})$ of the same cell in (c). The EC50 values of PS for the inward currents are $21.0 \pm 1.0 \mu \mathrm{M}$ at $\mathrm{pH} 7.2$ and $26.0 \pm 1.0 \mu \mathrm{M}$ at $\mathrm{pH} 6.0$.

Figure 4 Inhibitory effect of low intracellular pH on TRPM3 can be reversed by perfusing cells with extracellular solution containing $\mathrm{NH}_{4} \mathrm{Cl}$. (a) Time course showing outward and inward current, recorded at +100 and $-100 \mathrm{mV}$ respectively, obtained from HEK cells overexpressing TRPM3, under voltage ramp protocol ranging -100 to $+100 \mathrm{mV},\left(\mathrm{pH}_{\mathrm{i}}=6.0, \mathrm{n}=11\right.$ cells $)$. Indicated concentrations of $\mathrm{NH}_{4} \mathrm{Cl}$ was applied extracellularly along with PS. To achieve similar osmolarity, all extracellular $\mathrm{Na}^{+}$concentration was lowered to $85 \mathrm{mM}$ and osmolarities were adjusted to $300 \pm$ 10 mOsm by mannitol. Adequate washing time ( 1 - 3 minutes) was provided after each application of $\mathrm{NH}_{4} \mathrm{Cl}$, to bring the current down to the basal level, which is 6.0 for all the cells recorded. Representative current was plotted versus time in the presence of extracellular $\mathrm{NH}_{4} \mathrm{Cl}$ and $\mathrm{PS}$, at the indicated concentrations. To achieve similar osmolarity, all extracellular buffer $\mathrm{Na}^{+}$ concentration was lowered to $85 \mathrm{mM}$ and osmolarities were adjusted to $300 \pm 10 \mathrm{mOsm}$ by mannitol. (b) Representative recording of TRPM3 current by ramp protocols ranging from -100 $\mathrm{mV}$ to $+100 \mathrm{mV}$ at the indicated $\mathrm{NH}_{4} \mathrm{Cl}$ concentrations. (c) Mean outward and inward TRPM3 current at the indicated $\mathrm{NH}_{4} \mathrm{Cl}$ concentrations (mean $\pm \mathrm{SEM}, \mathrm{n}=11$ cells). * indicates $\mathrm{p}<0.05$ by unpaired Student's t-test. (d) Representative recording of TRPM3 current by the does-dependent effects of $\mathrm{NH}_{4} \mathrm{Cl}$. The applications of extracellular $\mathrm{NH}_{4} \mathrm{Cl}$ at the indicated concentrations. (e) Representative recording of TRPM3 current by ramp protocols ranging from $-100 \mathrm{mV}$ to $+100 \mathrm{mV}$ at the indicated $\mathrm{NH}_{4} \mathrm{Cl}$ concentration. (From panel d) (f) Mean outward and inward TRPM3 current at the indicated $\mathrm{NH}_{4} \mathrm{Cl}$ concentration. (From replicated experiment of panel D) (mean $\pm \mathrm{SEM}$, 
$\mathrm{n}=11$ cells). (g \&h) Concentration-dependence curves of effects of $\mathrm{NH}_{4} \mathrm{Cl}$ on TRPM3 activations, outward (g) and inward (h) currents, respectively. All currents were normalized to corresponding capacitance of the cell overexpressing hTRPM3 (mean $\pm \mathrm{SEM}, \mathrm{n}=11$ cells) at the indicated $\mathrm{NH}_{4} \mathrm{Cl}$ concentration. $\mathrm{EC}_{50}$ values were measured separately for outward $\left(\mathrm{NH}_{4} \mathrm{Cl}_{50}=2.7 \pm 0.3 \mu \mathrm{M}\right)$ currents, whereas the inward currents continues to increase after applying $60 \mathrm{mM} \mathrm{NH}_{4} \mathrm{Cl}$. (i) $\mathrm{Mean}$ ratio of inward current to outward current plotted against $\mathrm{NH}_{4} \mathrm{Cl}$ concentrations (mean $\pm \mathrm{SEM}$, $\mathrm{n}=11$ cells).

Figure 5 TRPM3 is potentially permeable to protons. (a) Schematic showing the protons permeation recording condition, where all intracellular and extracellular ions were replaced by NMDG and glutamic acid, respectively, except for protons. $50 \mu \mathrm{M}$ PS was applied while holding hTRPM3-GFP transfected HEK cells at $-100 \mathrm{mV}$. (b) Inward currents were elicited by PS application. No PS activated current under the NMDG solution at $\mathrm{pH}_{\mathrm{o}}$ 7.40, while lowering down the $\mathrm{pH}_{\mathrm{o}}$ to 5.50 generated a small and transient inward current. Insert panel shows the inward current recorded during NMDG-PS (pH 5.5) application. (c) Mean current amplitude in response to PS at the indicated conditions (mean \pm SEM, $n=8$ cells). (d) Relative current amplitude in response to PS, comparing with Tyrode $\left(\mathrm{pH}_{\mathrm{o}}\right.$ 7.4) solution response of the same cell (mean $\pm \mathrm{SEM}$, $\mathrm{n}=8$ cells $)$

Figure 6 Inhibitory effect of intracellular high $\mathrm{Ca}^{2+}$ on TRPM3 activation by PS. (a and b) Time course of TRPM3 currents elicited by voltage ramps ranging -100 to $+100 \mathrm{mV}$ at the indicated $\left[\mathrm{Ca}^{2+}\right]_{\mathrm{i}}$ concentration. At high $\left[\mathrm{Ca}^{2+}\right]_{\mathrm{i}}(1 \mu \mathrm{M})$, TRPM3 is activated by PS initially (Black symbol), but runs down soon afterwards (Red symbol). Whereas the TRPM3 current was sustained at the 
low $\left[\mathrm{Ca}^{2+}\right]_{i}$ condition. Inserts show the representative recordings from the indicated points. (c) Mean current amplitude of TRPM3 at the indicated $\left[\mathrm{Ca}^{2+}\right] \mathrm{i}($ mean $\pm \mathrm{SEM} ; \mathrm{n}=10)$. * indicates p $<0.05$ by unpaired Student's t-test; "n.s." indicates not statistically significant. (d) Time course and representative recordings of TRPM3 current with $\left[\mathrm{Ca}^{2+}\right]_{\mathrm{i}}(1 \mu \mathrm{M})$ at the indicated $\mathrm{pH}_{\mathrm{i}}$ from $\mathrm{pH}$ 8.0 to $\mathrm{pH}_{\mathrm{i}}$ 6.0. (e) $\mathrm{pH}$ concentration-dependence of TRPM3 activation by PS at the indicated $\left[\mathrm{Ca}^{2+}\right]_{i}$. Green and blue symbols both represent high $\left[\mathrm{Ca}^{2+}\right]$, while green represents currents elicited right after PS application (peak after onset), and blue represent currents remaining after inhibition of by high $\left[\mathrm{Ca}^{2+}\right]_{\mathrm{i}}(80 \mathrm{~s}$ after onset). All currents were normalized to corresponding capacitance of the cell overexpressing hTRPM3. Each data point is the mean of 8-14 cells with the error bar showing $\mathrm{SEM}$, at the indicated $\mathrm{pH}_{\mathrm{i}}$. (f) Mean ratio of the peak current after onset to the current 80 seconds after onset (mean \pm SEM, $n=8-14$ cells). "n.s." indicates not statistically significant among groups by one-way ANOVA with Tukey's post hoc multiple comparison.

Figure 7 Changes of protons sensitivity of TRPM3 mutants. (a) Schematic of TRPM3 structure and the substituted amino acid residues in the putative pore region of hTRPM3. (b) Time course and representative recordings of TRPM3 mutants and wild-type currents elicited by voltage ramps ranging -100 to $+100 \mathrm{mV}$, at the indicated $\mathrm{pH}_{\mathrm{o}}$. Bar graphs show mean outward and inward current amplitudes at the indicated $\mathrm{pH}_{\mathrm{o}}$ (mean $\pm \mathrm{SEM}, \mathrm{n}=7-12$ cells) Internal solution had a constant $\mathrm{pH}$ of 7.20 for all the recordings. (c) Ratio of outward current amplitudes at $\mathrm{pHo}$ 5.5 and $\mathrm{pH}_{\mathrm{o}} 7.4$, of TRPM3 mutants and WT control. To obtain these ratios, current elicited by $+100 \mathrm{mV}$ at $\mathrm{pH}_{\mathrm{o}} 5.5$ was divided by the current elicited by $+100 \mathrm{mV}$ at $\mathrm{pH}_{\mathrm{o}} 7.4$ of the same cell $(\mathrm{n}$ $=7-12$ cells). $\mathrm{P}$ values, comparing each group with WT-TRPM3, * indicates $\mathrm{p}<0.05$ by unpaired Student's t-test; "n.s." indicates not statistically significant. 
Supplementary Figure 1 Concentration-dependent effects of $\mathrm{NH}_{4} \mathrm{Cl}$ on TRPM3 current. (a)Time course and representative recordings of TRPM3 current by ramp protocols ranging from - $100 \mathrm{mV}$ to $+100 \mathrm{mV}$ at the indicated $\mathrm{NH}_{4} \mathrm{Cl}$ concentrations. The $\mathrm{pH}_{\mathrm{i}}$ was 6.0 in all recordings. Individual transfected cells were exposed to $\mathrm{NH}_{4} \mathrm{Cl}$ only once. (b)The comparison of effects of $\mathrm{NH}_{4} \mathrm{Cl}$ on TRPM3 currents in "gradient" (Fig.4) and "individual" (a) recordings. The increase in outward current in response to $\mathrm{NH}_{4} \mathrm{Cl}$ is presented as the percentage increase in outward current from the same cell without $\mathrm{NH}_{4} \mathrm{Cl}$. Both data suggest that $\mathrm{NH}_{4} \mathrm{Cl}$ potentiate both TRPM3 inward and outward currents. The average data are mean $\pm \mathrm{SEM}, \mathrm{n}=11-20$ cells 


\section{Fig.1}

A

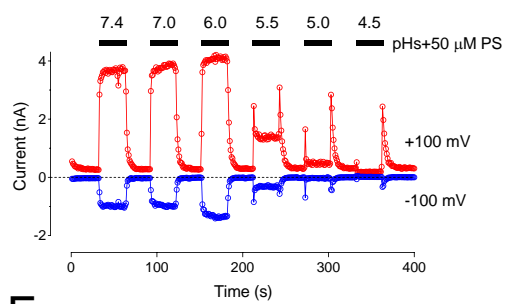

E

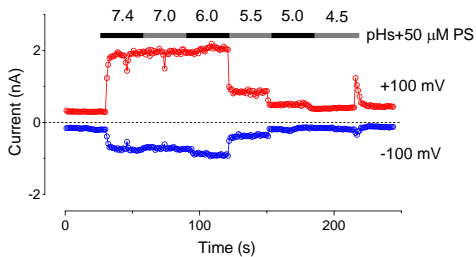

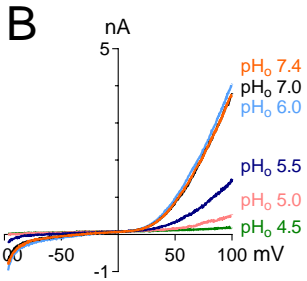

$\mathrm{F}$

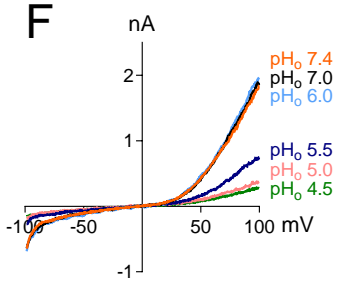

C
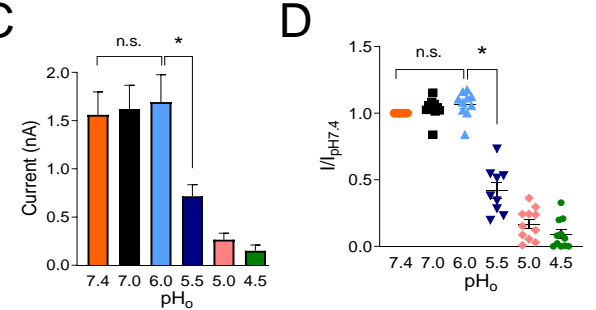

G

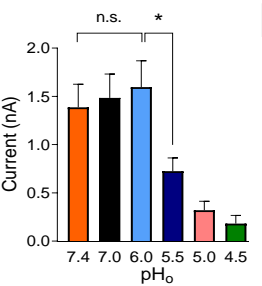

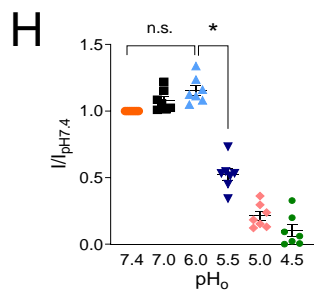




\section{Fig.2}

A
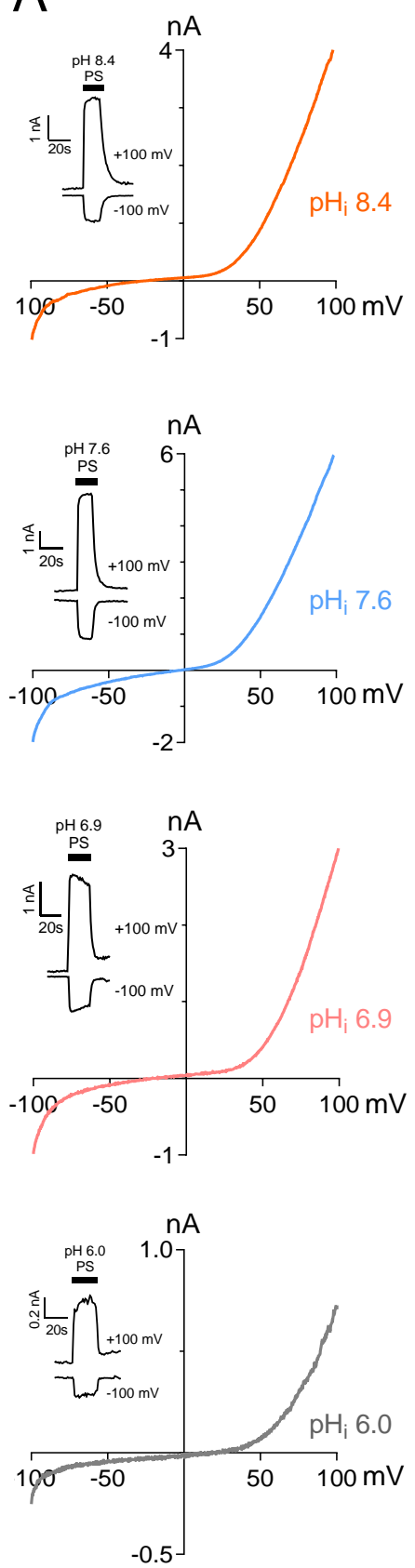
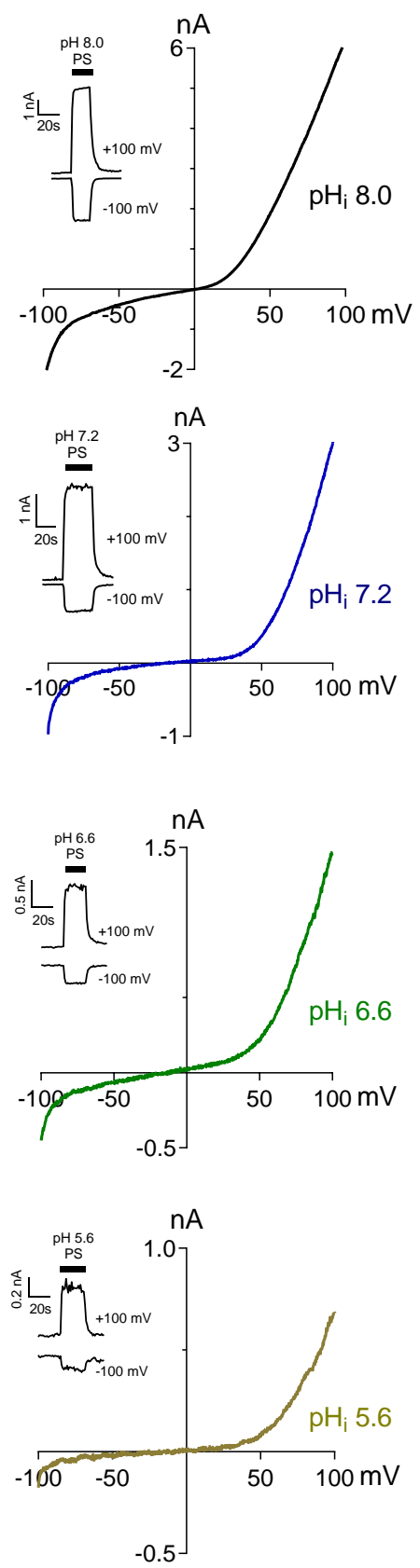

B

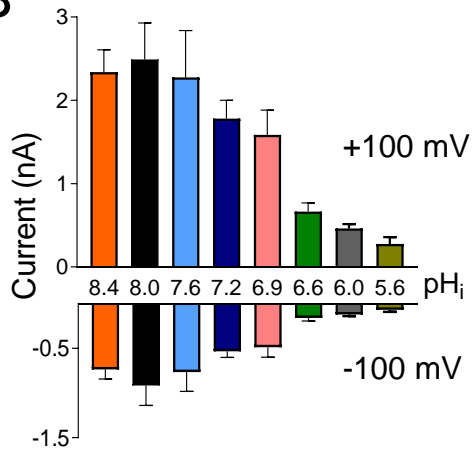

C



D $\mathrm{pH}_{\mathrm{i}}$

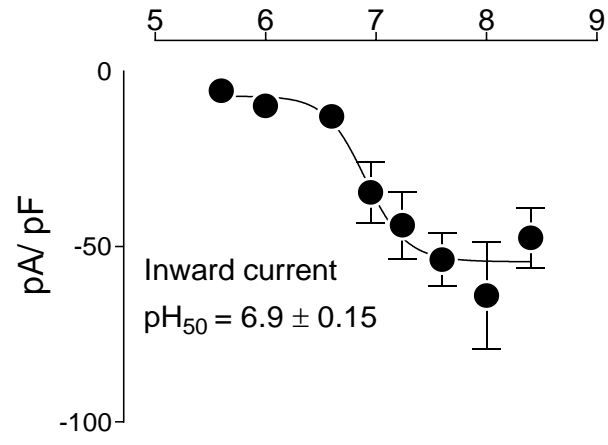




\section{Fig.3}
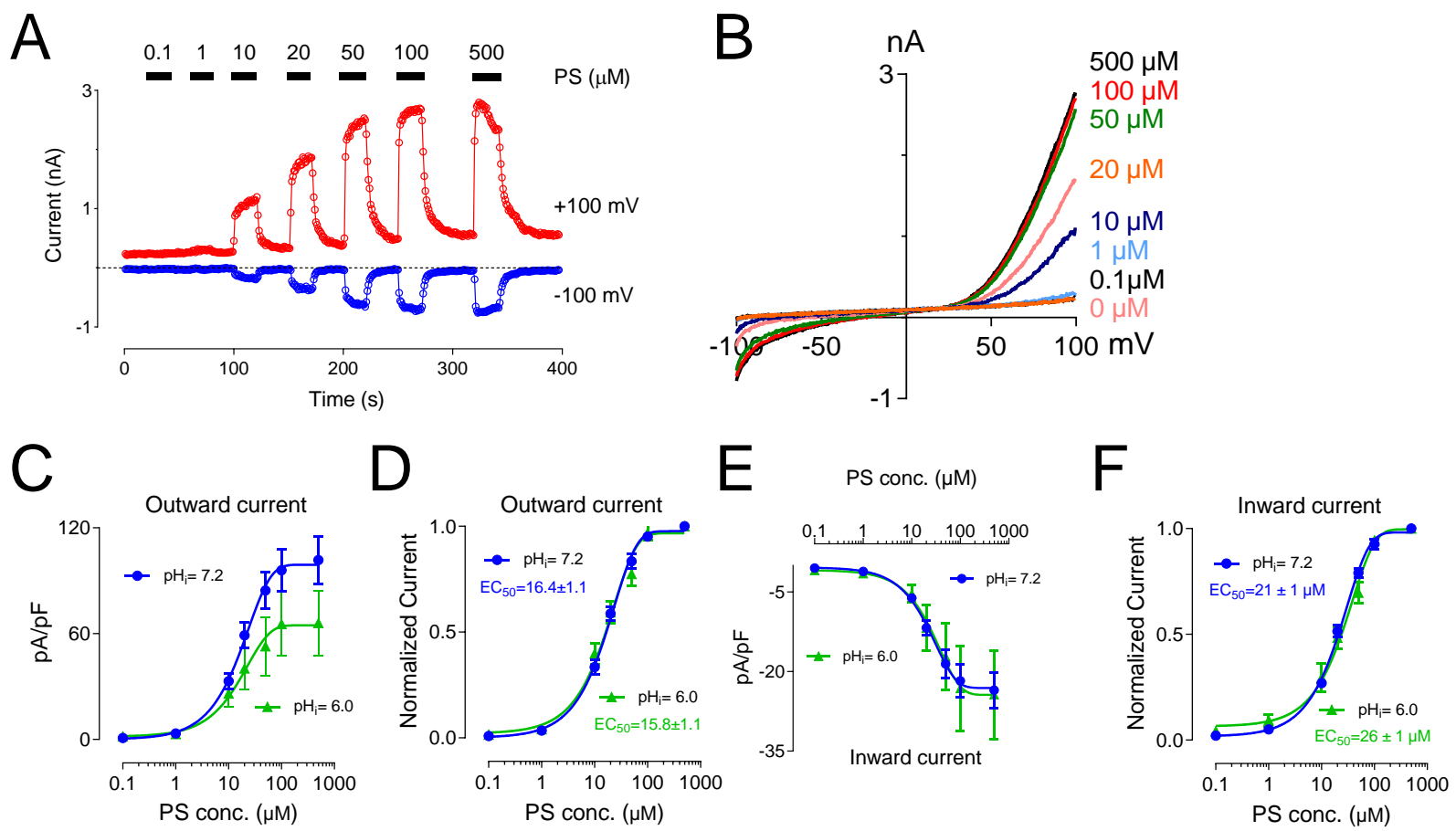


\section{Fig.4}

A

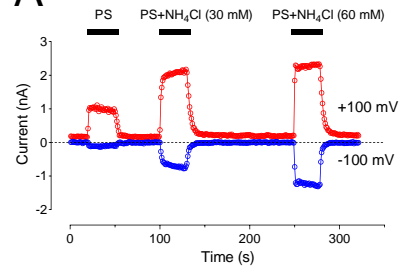

E

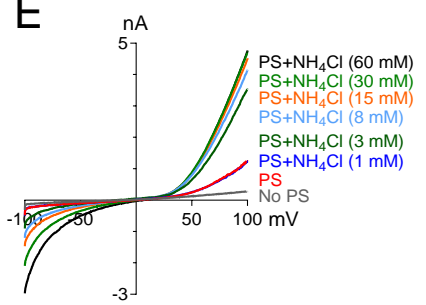

B

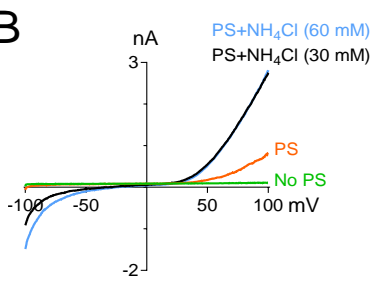

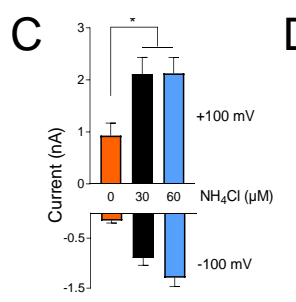

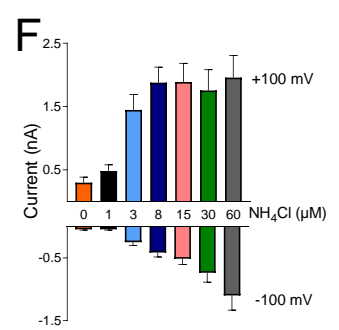

G

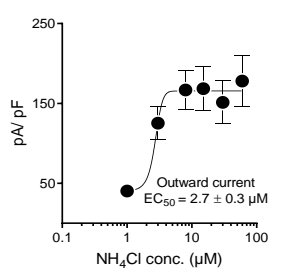

$\mathrm{H}$

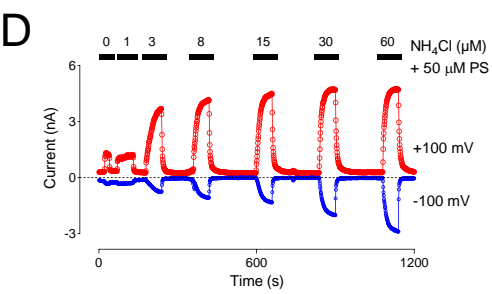

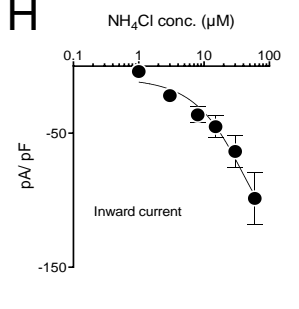

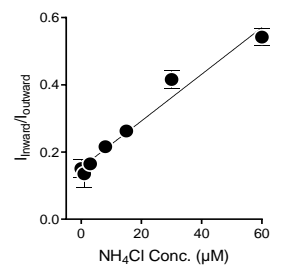


bioRxiv preprint doi: https://doi.org/10.1101/2020.10.08.331454; this version posted October 8,2020 . The copyright holder for this preprint (which was not certified by peer review) is the author/funder, who has granted bioRxiv a license to display the preprint in perpetuity. It is made available under aCC-BY-NC 4.0 International license.

\section{Fig.5}
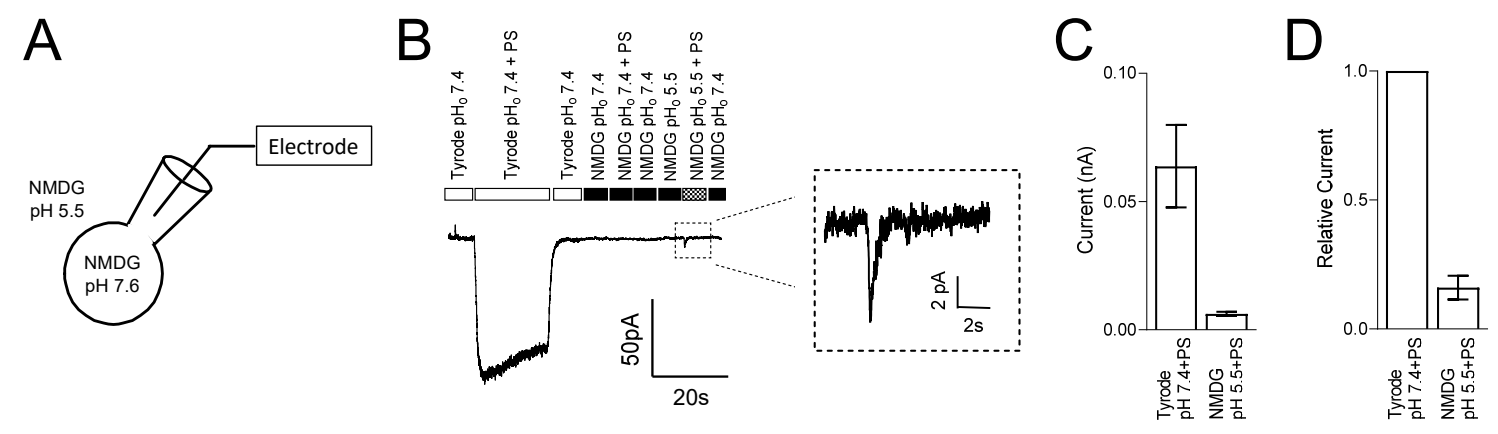


\section{Fig.6}

A

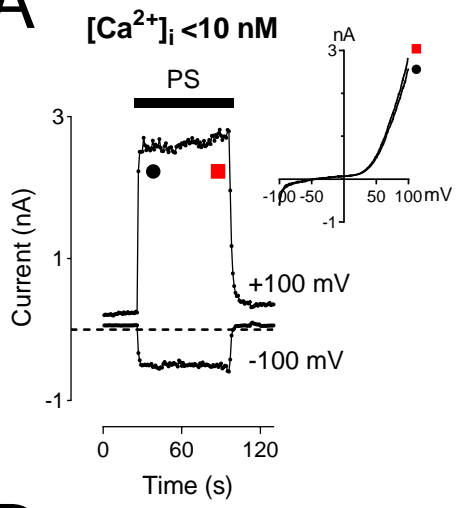

D $\quad \mathrm{pH}_{\mathrm{i}}=8.0$
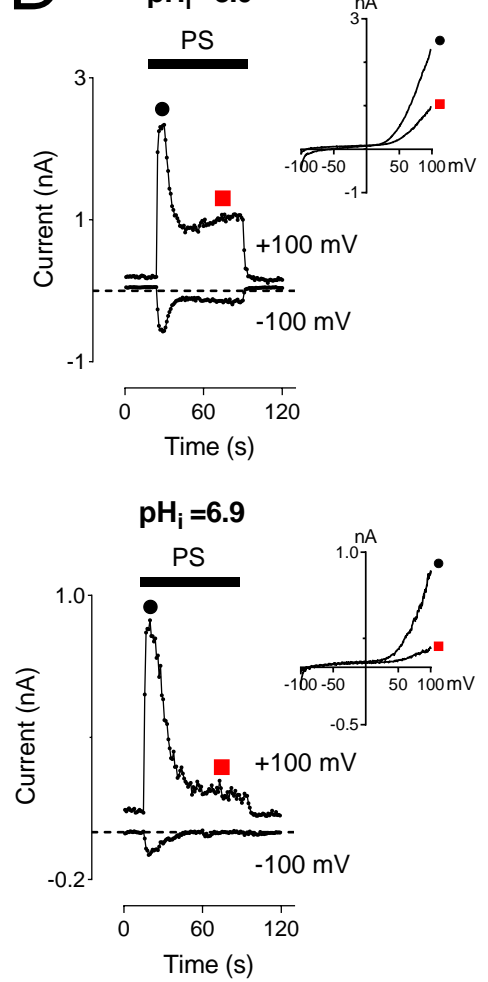

$E$

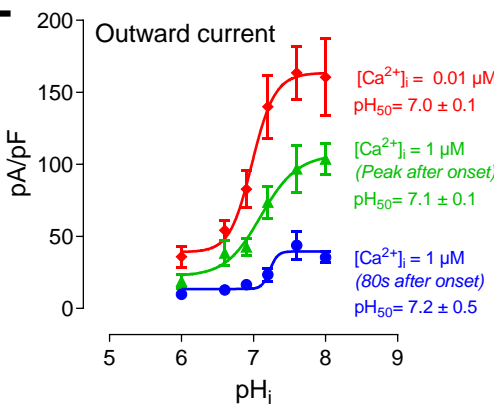

B
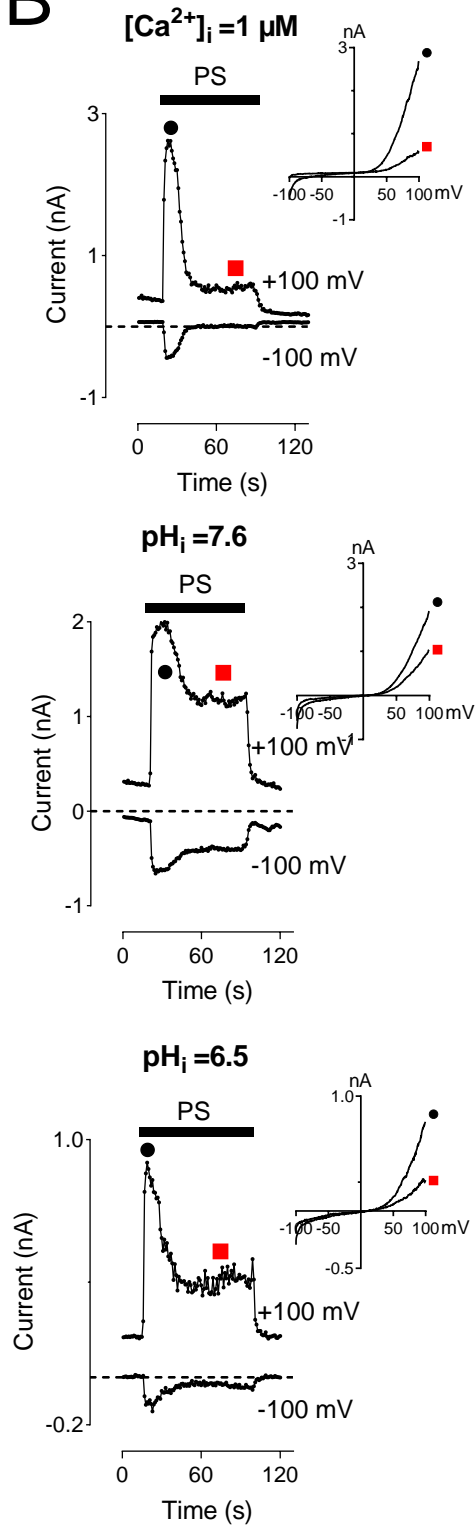

$\mathrm{F}$

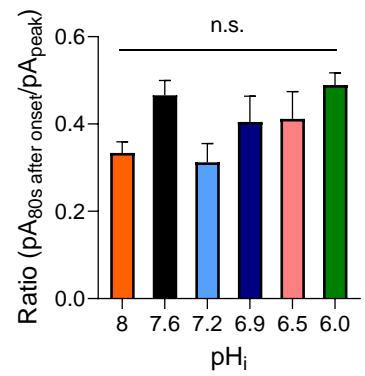

C
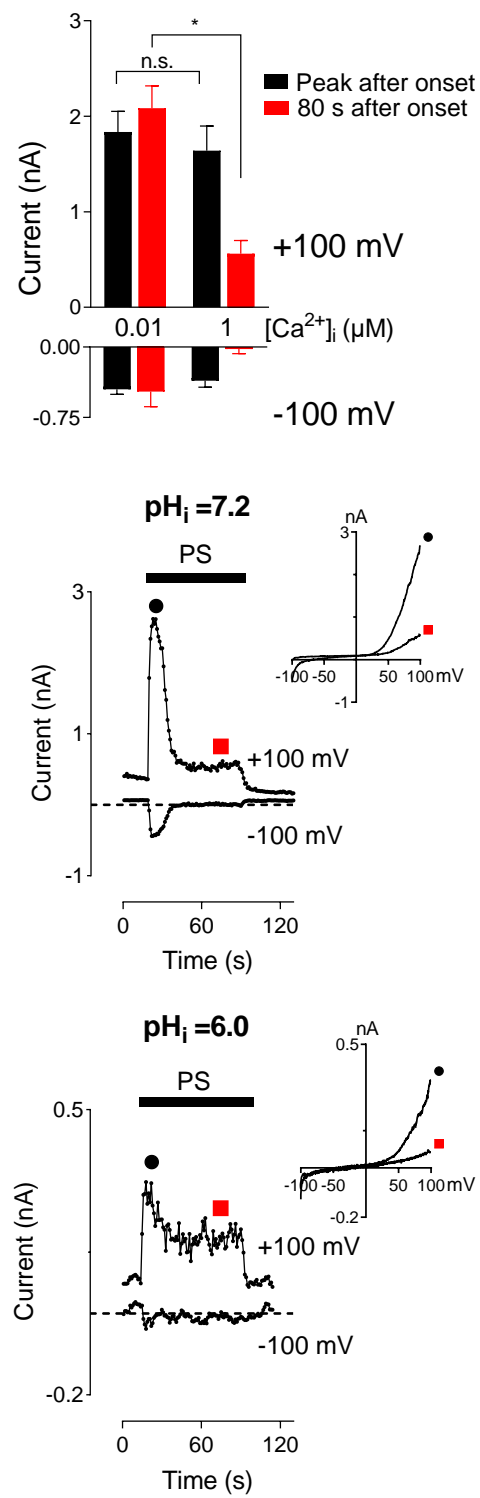
Fig.7

A

TRPM3 structure

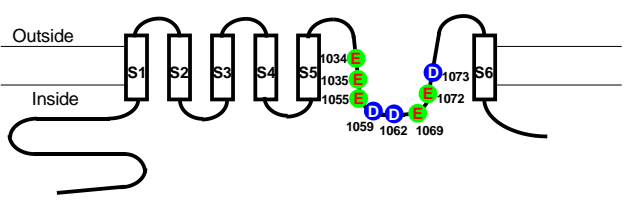

B
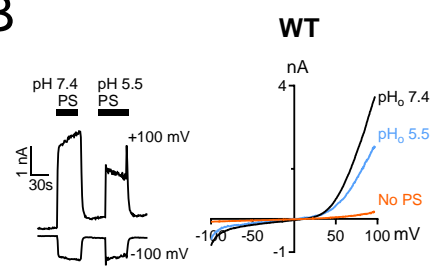

|-100 mV

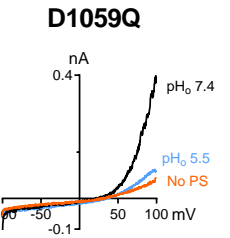

E1069Q
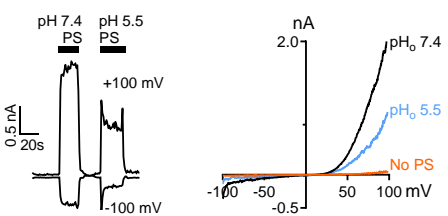

E1072Q
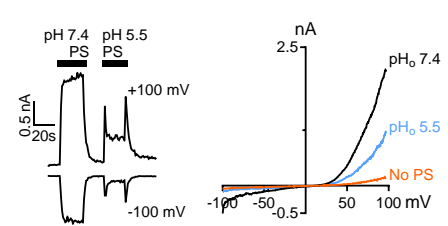
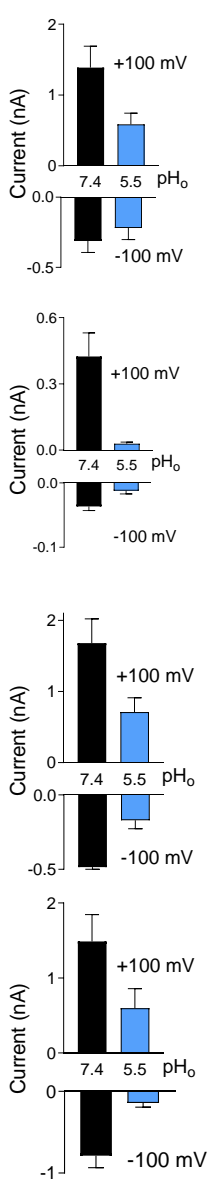

C

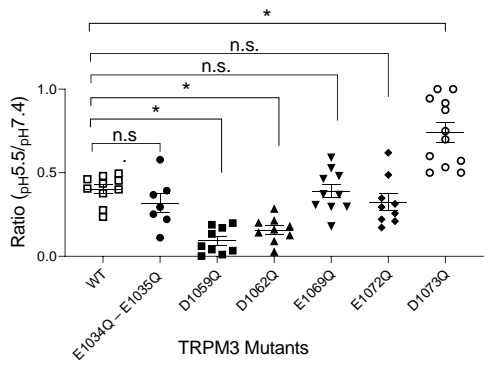

E1034Q-E1035Q
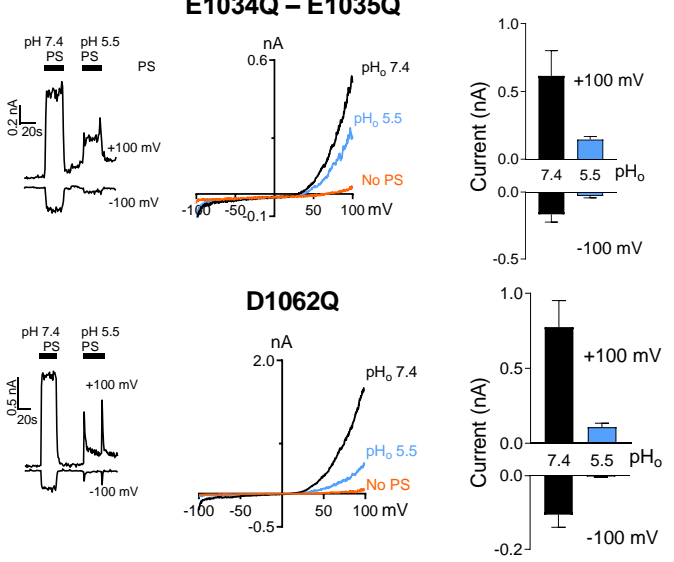

E1072Q-D1073Q



\section{sFig.1}

A
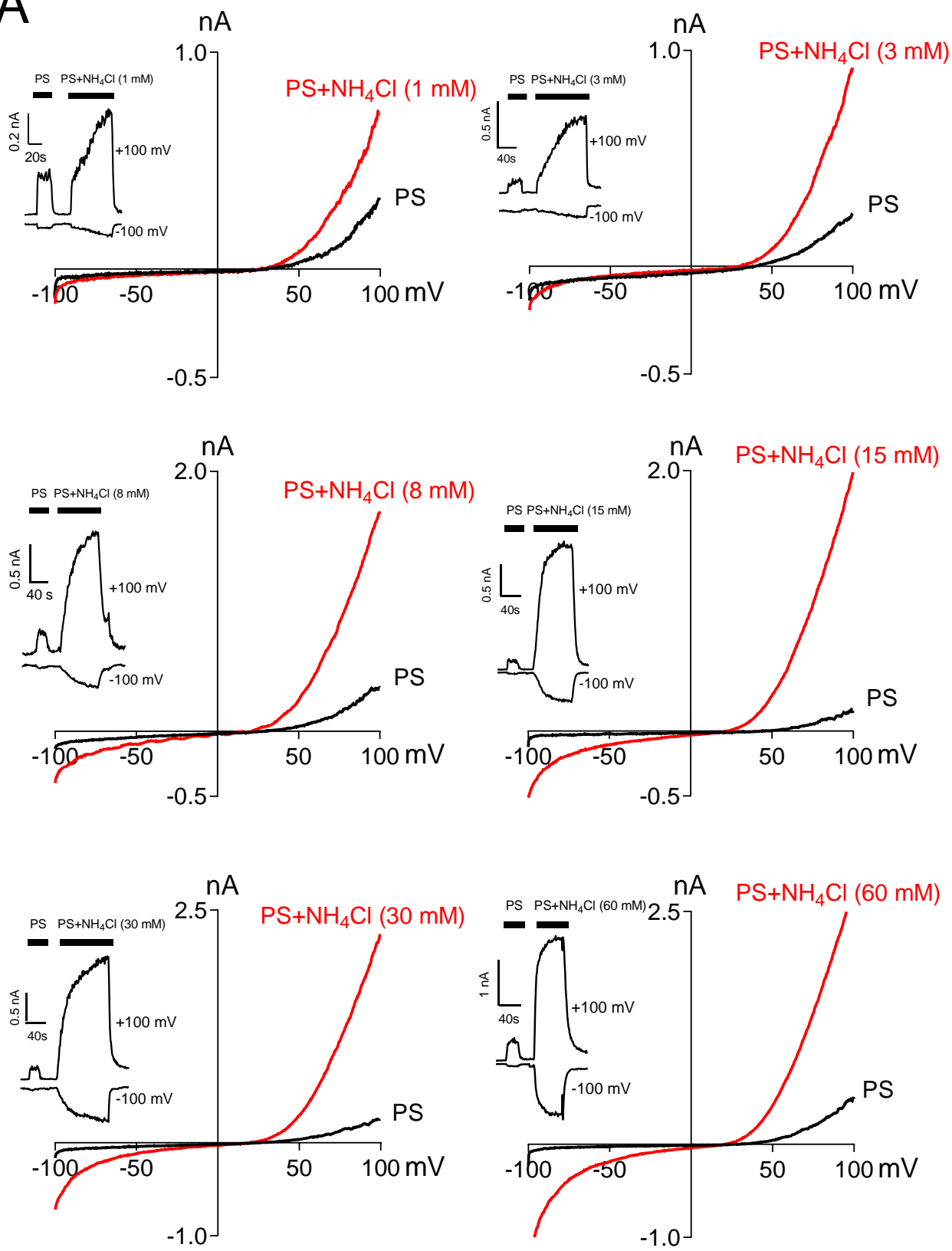

$\mathrm{B}$

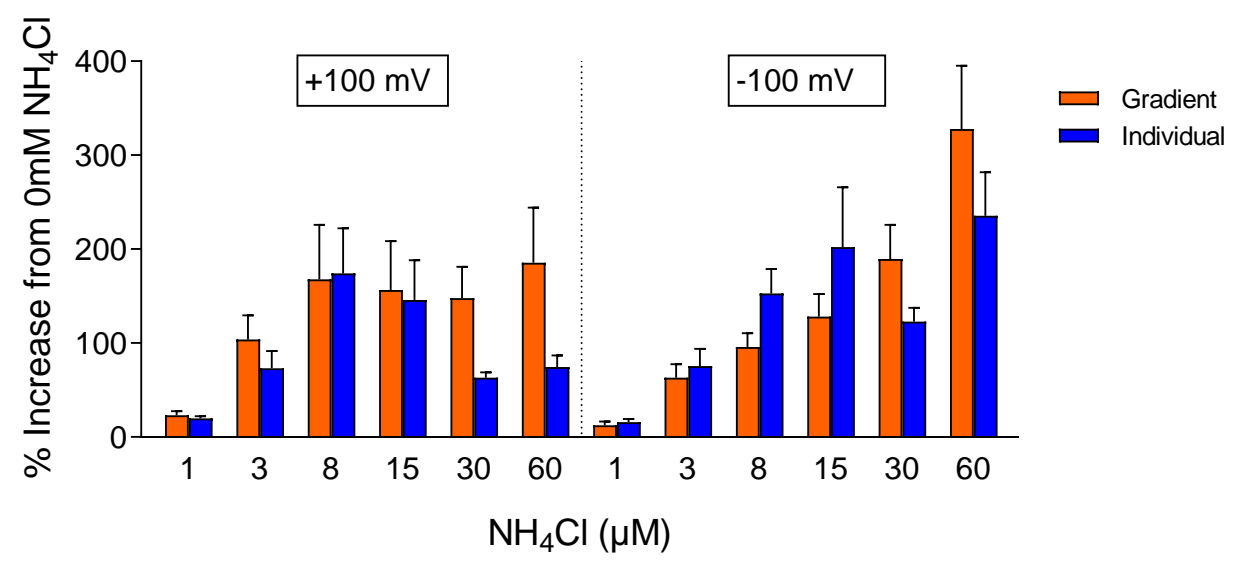

